\section{Autophagy-dependent ribosomal RNA degradation is essential for maintaining nucleotide homeostasis during $C$. elegans development}

\author{
Yubing Liu ${ }^{1,2,3}$, Wei Zou ${ }^{2}$, Peiguo Yang ${ }^{3}$, Li Wang ${ }^{3,4}$, Yan $\mathrm{Ma}^{2}$, Hong Zhang ${ }^{3,4}$, \\ Xiaochen Wang ${ }^{3,4 *}$
}

${ }^{1}$ Peking University-Tsinghua University-National Institute of Biological Joint Graduate Program, School of Life Sciences, Peking University, Beijing, China; ${ }^{2}$ National Institute of Biological Science, Beijing, China; ${ }^{3}$ National Laboratory of Biomacromolecules, CAS Center for Excellence in Biomacromolecules, Institute of Biophysics, Chinese Academy of Sciences, Beijing, China; ${ }^{4}$ College of Life Sciences, University of Chinese Academy of Sciences, Beijing, China

\begin{abstract}
Ribosome degradation through the autophagy-lysosome pathway is crucial for cell survival during nutrient starvation, but whether it occurs under normal growth conditions and contributes to animal physiology remains unaddressed. In this study, we identified RNST-2, a $C$. elegans T2 family endoribonuclease, as the key enzyme that degrades ribosomal RNA in lysosomes. We found that loss of rnst-2 causes accumulation of rRNA and ribosomal proteins in enlarged lysosomes and both phenotypes are suppressed by blocking autophagy, which indicates that RNST-2 mediates autophagic degradation of ribosomal RNA in lysosomes. rnst-2(If) mutants are defective in embryonic and larval development and are short-lived. Remarkably, simultaneous loss of RNST-2 and de novo synthesis of pyrimidine nucleotides leads to complete embryonic lethality, which is suppressed by supplements of uridine or cytidine. Our study reveals an essential role of autophagy-dependent degradation of ribosomal RNA in maintaining nucleotide homeostasis during animal development.
\end{abstract}

wangxiaochen@ibp.ac.cn

Competing interests: The authors declare that no competing interests exist.

Funding: See page 19

Received: 12 March 2018

Accepted: 12 August 2018

Published: 13 August 2018

Reviewing editor: Noboru Mizushima, The University of Tokyo, Japan

(c) Copyright Liu et al. This article is distributed under the terms of the Creative Commons Attribution License, which permits unrestricted use and redistribution provided that the original author and source are credited.
DOI: https://doi.org/10.7554/eLife.36588.001

\section{Introduction}

Macroautophagy (hereafter referred to as autophagy) delivers cytoplasmic materials such as protein aggregates and organelles to lysosomes for degradation. The resulting catabolites are reutilized to maintain cellular homeostasis under both stress and physiological conditions (Mizushima, 2009; Levine et al., 2011). During autophagy, bulk cytosol may be randomly sequestered into doublemembrane autophagosomes, which eventually fuse with lysosomes where cargos are degraded (Xie and Klionsky, 2007; Nakatogawa et al., 2009). On the other hand, specific substrates can be recognized and removed through selective autophagy (Cebollero et alo, 2012). In both cases, multiple protein complexes act coordinately to control the initiation, formation and maturation of autophagosomes as well as their fusion with lysosomes (Nakatogawa et al., 2009; Yang and Klionsky, 2010).

A variety of cellular components including organelles are found to be substrates of autophagy. Ribosomes were among the first few cargos detected in the interior of autophagosomes by electron microscopy and have served as a marker of bulk cytoplasm degradation (Ashford and Porter, 1962; Eskelinen et al., 2011). In addition to non-selective autophagy, prolonged nitrogen starvation in 
yeast leads to ribophagy, during which mature ribosomes are selectively targeted and removed by autophagy (Kraft et al., 2008). In ribophagy, the large and small ribosomal subunits appear to be independently targeted for degradation, which involves both ubiquitination and deubiquitination (Kraft et al., 2008; Kraft and Peter, 2008; Ossareh-Nazari et al., 2010; Ossareh-Nazari et al., 2014; Dargemont and Ossareh-Nazari, 2012). Ribosomes contain about $50 \%$ of the cellular proteins and $80 \%$ of total RNA. Both ribosomal proteins and RNAs are processed in lysosomes during autophagy-mediated degradation, which may serve as the major source of amino acids and nucleotides in nutrient deprivation conditions (Huang et al., 2015; Lafontaine, 2010). It is therefore not surprising that autophagic degradation of ribosomes is crucial for survival of yeast cells in nutrient starvation (Kraft et al., 2008). However, it remains unclear whether mature ribosomes are degraded through autophagy under normal growth conditions and whether ribosome degradation contributes to animal physiology.

C. elegans embryos are wrapped in tough eggshells that are impermeable to most solutes. The development of embryos from the one-cell stage to the end of embryogenesis (558 cells) relies on degradation of maternally loaded materials, independent of external nutrients. The maternally loaded yolk proteins are degraded in lysosomes, while PGL granules and aggregates of SOST-1/p62 and SEPA-1 family proteins are removed by autophagy (Lin et al., 2013; Tian et al., 2010; Zhang et al., 2009; Liu et al., 2012). The resulting catabolites are recycled from lysosomes to provide energy and essential building blocks for embryogenesis. Impairing autophagy or lysosome function leads to reduced hatching rate and retarded embryonic development (Zhao et al., 2009; Tian et al., 2009; Liu et al., 2012; Sun et al., 2011). It is unclear whether ribosomes, which contain abundant proteins and RNAs, may be used as a nutrient source for development.

In this study, we identified RNST-2, the C. elegans T2 family endoribonuclease, from a genetic screen for lysosome-defective mutants. We found that loss of RNST-2 causes accumulation of rRNA and ribosomal proteins in lysosomes in an autophagy-dependent manner. rnst-2(If) worms are defective in embryonic and larval development and have shortened lifespans. Our data indicate that autophagy-dependent degradation of ribosomal RNA is important for maintaining nucleotide homeostasis, which is essential for development.

\section{Results}

\section{qx245 mutants contain abnormal lysosomes}

From a forward genetic screen for mutants with lysosomal defects, we isolated qx245, which contained abnormally enlarged lysosomes. In wild type, lysosomes labeled by the lysosomal membrane protein LAAT-1::GFP and the lysosomal DNase II NUC-1::CHERRY appeared as small puncta and thin tubules, with an average volume of $0.77 \mu \mathrm{m}^{3}$ in 4-fold embryos and L1 larvae (Figure 1A,D,G,J, $M$ and Figure 1-figure supplement 1A,D,G,J,M,P) (Guo et al., 2010; Liu et al., 2012). In qx245 mutants, however, enlarged lysosomes were observed at embryonic, larval and adult stages in multiple cell types including hypodermal cells, muscle cells and sheath cells (Figure $1 B, E, H, K$ and Figure 1-figure supplement $1 B, E, H, J, K, M, N)$. The average volume of lysosomes reached $2.85 \mu \mathrm{m}^{3}$ in qx245 embryos and L1 larvae, and $5.67 \mu \mathrm{m}^{3}$ in adult hypodermis, which is 3.7 and 2.5 times bigger than in wild type, respectively (Figure $1 \mathrm{M}$ and Figure 1-figure supplement 1P). The enlargement of lysosomes in qx245 was observed from late embryonic to early larval stages, and at the adulthood (Figure 1-figure supplement 10). We found that the enlarged lysosomes in $q \times 245$ mutants were stained by Lysotracker Red to a similar extent as in wild type, suggesting that lysosome acidification is not affected (Figure $1 \mathrm{~J}-K^{\prime \prime}, \mathbf{N}$ and Figure 1-figure supplement $1 R$ ).

\section{qx245 affects RNST-2, a widely expressed lysosomal T2 endoribonuclease}

The q×245 mutation affects the gene rnst-2, which encodes a T2 family endoribonuclease (RNase T2) (Figure 1-figure supplement 2A and L). RNase T2 family enzymes catalyze cleavage of singlestranded RNA at all four bases with an optimal pH of 4-5 (Luhtala and Parker, 2010). These enzymes perform diverse functions in a wide variety of organisms by processing extracellular and intracellular RNAs (Luhtala and Parker, 2010). We found that qx245 carried a G-to-A mutation in rnst-2 that resulted in the replacement of Gly 119 by Glu (Figure 1-figure supplement 2L). bp555, 


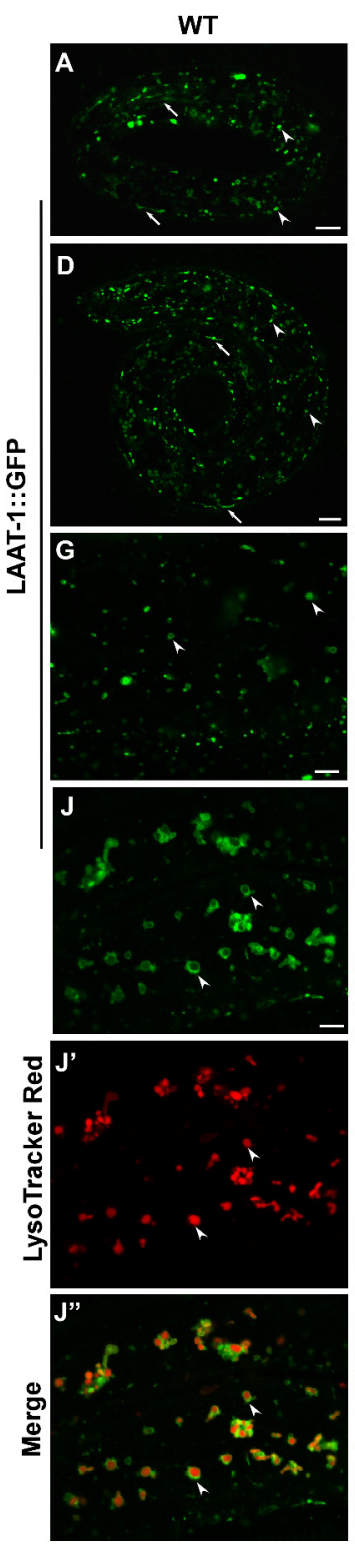

M
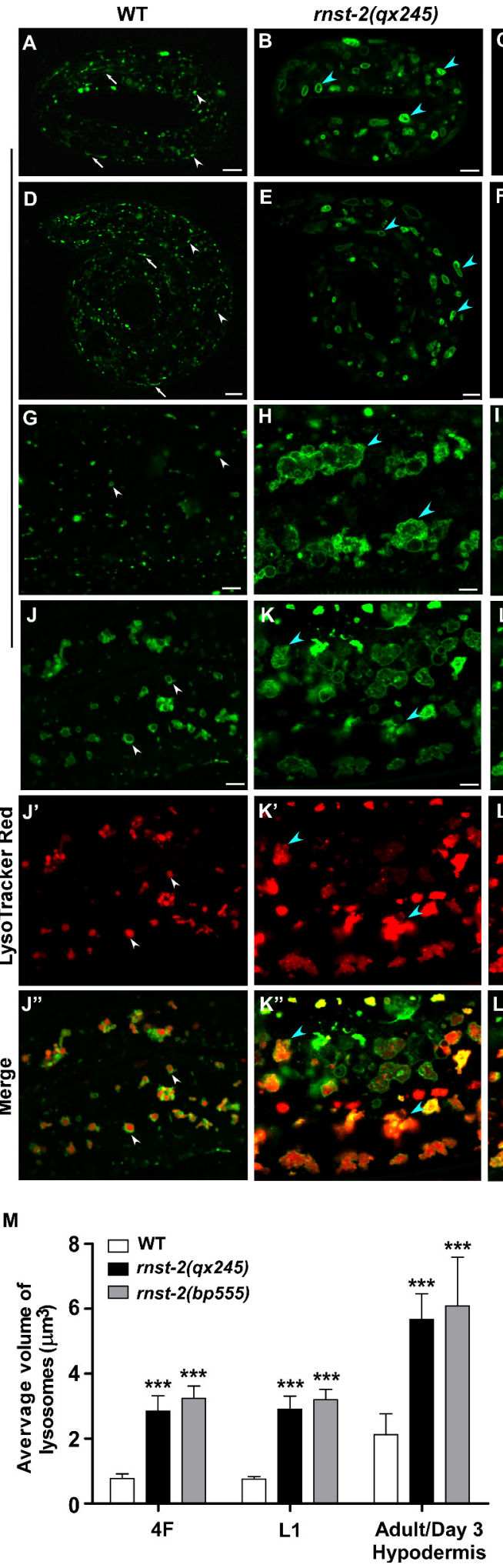
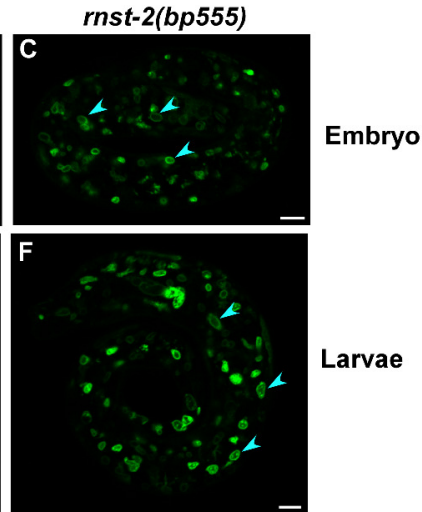

Larvae
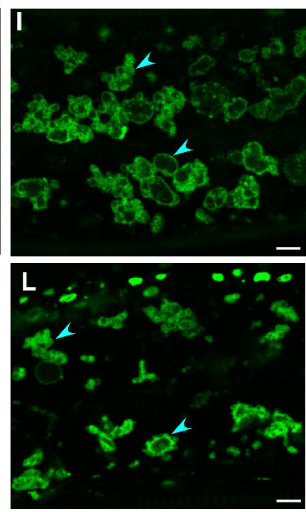

Adult/

Hypodermis

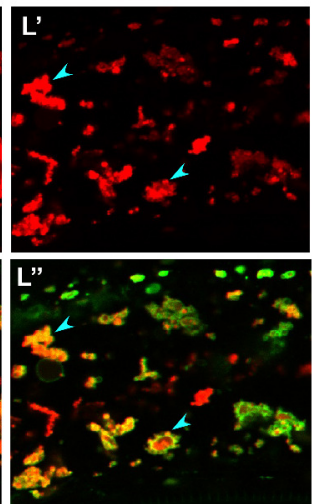

$\mathbf{N}$

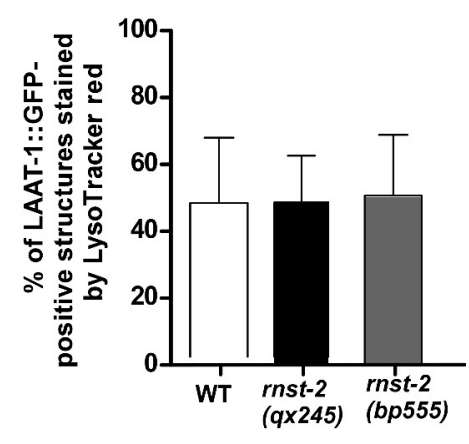

Figure 1. rnst-2 mutants accumulate enlarged lysosomes. (A-I) Confocal fluorescence images of embryos at the 4-fold stage (4F, A-C), larvae 1 (L1, DF) and adult hypodermis (G-I) in wild-type (WT, A, D, G), rnst-2(qx245) (B, E, H) and rnst-2(bp555) (C, F, I) expressing LAAT-1::GFP. (J-L") Confocal fluorescence images of the hypodermis in wild-type $\left(\mathrm{J}-\mathrm{J}^{\prime \prime}\right)$, rnst-2 (qx245) (K-K") and rnst-2(bp555) (L-L") adults expressing LAAT-1::GFP and stained by Lysotracker red. In $\left(\mathbf{A}-\mathrm{L}^{\prime \prime}\right)$, white arrowheads and arrows indicate globular and tubular lysosomes, respectively, and blue arrowheads indicate enlarged Figure 1 continued on next page 
Figure 1 continued

globular lysosomes. Scale bars: $5 \mu \mathrm{m}$. (M) Quantification of the average volume of lysosomes labeled by LAAT-1::GFP in 4-fold-stage embryos (4F), L1 larvae (L1) and adult hypodermis (day 3 of adulthood). (N) The percentage of LAAT-::GFP-positive lysosomes that were stained by lysotracker red was quantified in adult hypodermis. In (M, N), at least 10 worms were scored in each strain at each stage. Data are shown as mean \pm SD. Two-way ANOVA with the Bonferroni post hoc test (M) or one-way ANOVA with Tukey's post hoc test $(\mathrm{N})$ was performed to compare mutant datasets with wild type.

${ }^{* * *} p<0.001$, other points had $p>0.05$.

DOI: https://doi.org/10.7554/eLife.36588.002

The following source data and figure supplements are available for figure 1:

Source data 1. Figure 1 numerical data.

DOI: https://doi.org/10.7554/eLife.36588.005

Source data 2. Figure 1-figure supplement 1 numerical data.

DOI: https://doi.org/10.7554/eLife.36588.006

Figure supplement 1. rnst-2 mutants accumulate enlarged lysosomes in multiple cell types.

DOI: https://doi.org/10.7554/eLife.36588.003

Figure supplement 2. Molecular cloning of rnst-2.

DOI: https://doi.org/10.7554/eLife.36588.004

an independently isolated rnst-2 mutant allele, caused a premature stop codon after Pro 55. The G119E mutation in qx245 affected the second catalytic active site (CAS II), whereas both CAS I and II were lost in bp555, suggesting that $q \times 245$ and bp555 are strong loss-of-function or null mutations of rnst-2 (Figure 1-figure supplement 2L). Consistent with this, enlarged lysosomes were observed in bp555, like in qx245 (Figure $1 C, F, I, L, M$ and Figure 1 -figure supplement $1 C, F, I, L, O, P$ ). C. elegans RNST-2 shares $47 \%$ sequence similarity and $29 \%$ sequence identity with human RNASET2 (Figure 1-figure supplement 2L). Expression of RNST-2 or human RNASET2 controlled by the rnst-2 promoter efficiently rescued the enlarged lysosome phenotype in qx245 mutants, suggesting that RNASET2 can substitute for worm RNST-2 in maintaining lysosome morphology (Figure 1-figure supplement 2C,E-G,I).

We generated a RNST-2::CHERRY reporter driven by the rnst-2 promoter, which fully rescued the lysosome phenotypes in qx245 and bp555 mutants (Figure 1-figure supplement 2C, $F, G, J, K$ ). RNST-2::CHERRY was widely expressed from embryonic stages throughout larval and adult stages in various tissues, including pharynx, hypodermis, muscle, sheath cells, intestine cells, vulva and tail region (Figure $2 \mathrm{~A}-\mathrm{H}^{\prime}$ ). RNST-2::CHERRY stained both puncta and tubular structures that were labeled by the lysosomal membrane proteins LAAT-1::GFP and SCAV-3::GFP, indicating that RNST2 localizes to lysosomes (Figure 2I-J").

\section{rnst-2(If) lysosomes accumulate rRNA and ribosomal proteins in an autophagy-dependent manner}

To determine whether RNST-2 functions as a ribonuclease in lysosomes, we performed rescue experiments. Expression of wild-type RNST-2, but not RNST-2(H118A), which carries a mutation in the histidine residue $(\mathrm{H} 118)$ essential for the catalytic activity of endoribonuclease T2 (Kawata et al., 1990), rescued the enlarged lysosome phenotype of rnst-2(qx245) mutants, indicating that catalytic activity of RNST-2 is important for its function in lysosomes (Figure 1-figure supplement 2C, D, G, H). We purified lysosomes from wild type and rnst-2 worms and extracted RNA from lysosomes (Figure 3-figure supplement 1A,B) (Liu et al., 2012). We found that rnst-2(qx245) and rnst-2(bp555) lysosomes accumulated high levels of RNA, especially 26S and 18S rRNA (Figure 3A and Figure 3figure supplement $1 C$ ). The total RNA level in rnst-2 lysosomes was more than five times higher than in wild type (Figure 3A and Figure 3-figure supplement 1C). Moreover, lysosomal accumulation of ribosomal proteins from the large and small subunits was observed in rnst-2(qx245) and rnst2(bp555) but not wild-type worms (Figure 3B and Figure 3-figure supplement 1D). The lysosomal accumulation of RNA and ribosomal proteins in rnst-2(qx245) mutants was fully suppressed by expression of RNST-2 (Figure 3A and B). These data indicate that loss of RNST-2 disrupts ribosomal RNA degradation in lysosomes. The defective degradation of rRNA in rnst-2 lysosomes may impair further digestion of ribosomes, causing accumulation of ribosomal proteins in lysosomes.

We next investigated whether autophagy is responsible for delivering ribosomal RNA to lysosomes. ATG-2/ATG2 and EPG-6/WIPI4 regulate autophagosome formation and loss of their 


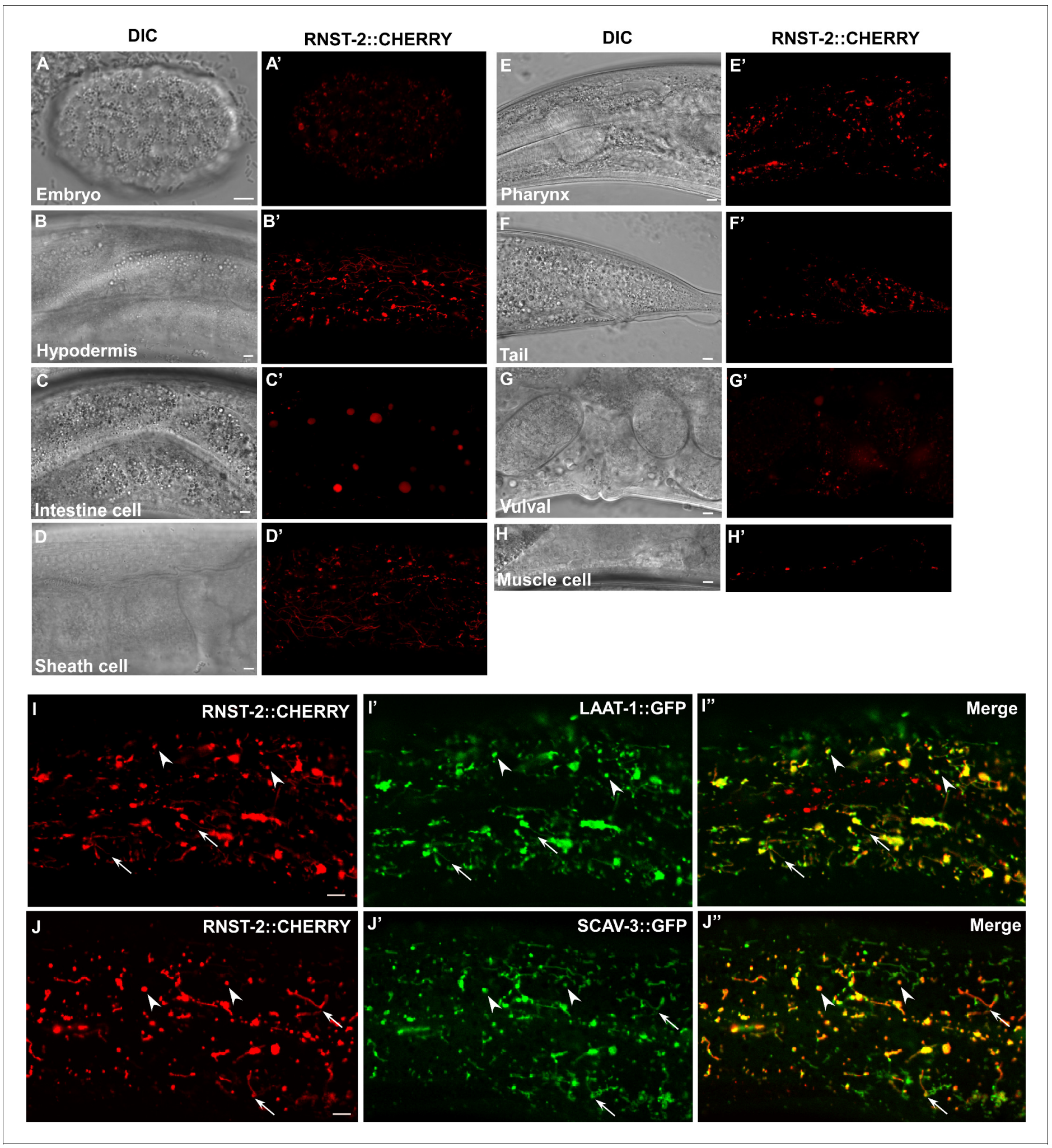

Figure 2. RNST-2 is widely expressed and localizes to lysosomes. (A-H') DIC and confocal fluorescence images of wild type expressing RNST-2:: CHERRY driven by the rnst-2 promoter. RNST-2::CHERRY is expressed from early embryos $\left(\mathbf{A}^{\prime} \mathbf{A}^{\prime}\right)$ to the adult stage in various cell types including hypodermis $\left(B, B^{\prime}\right)$, intestine $\left(C, C^{\prime}\right)$, sheath cell $\left(D, D^{\prime}\right)$, pharynx $\left(E, E^{\prime}\right)$, tail $\left(F, F^{\prime}\right)$, vulva $\left(G, G^{\prime}\right)$ and muscle cell $\left(H, H^{\prime}\right)$. $\left(I-J^{\prime \prime}\right)$ Confocal fluorescence images of the hypodermis in wild type co-expressing RNST-2::CHERRY and LAAT-1::GFP (I-I") or SCAV-3::GFP (J-J"). RNST-2 colocalizes with LAAT-1 and SCAV-3 to both globular (arrowheads) and tubular (arrows) lysosomes. Scale bars: $5 \mu \mathrm{m}$. DOI: https://doi.org/10.7554/eLife.36588.007 
A

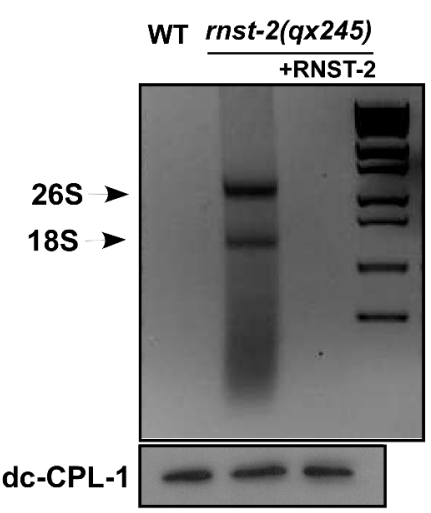

C

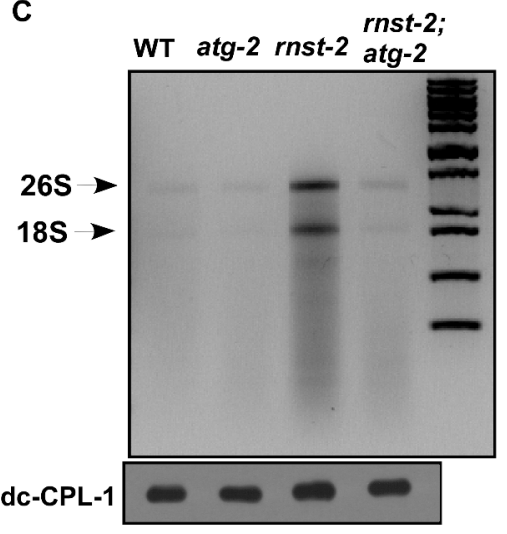

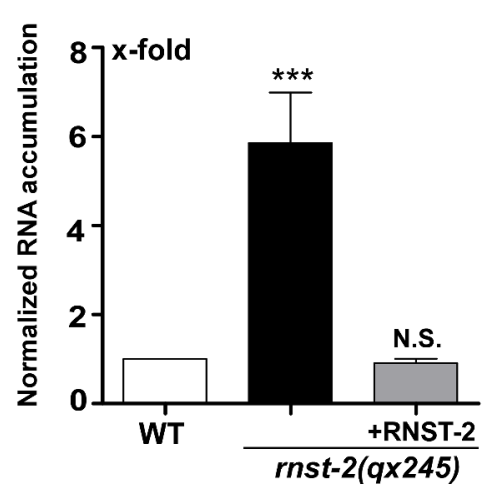

B

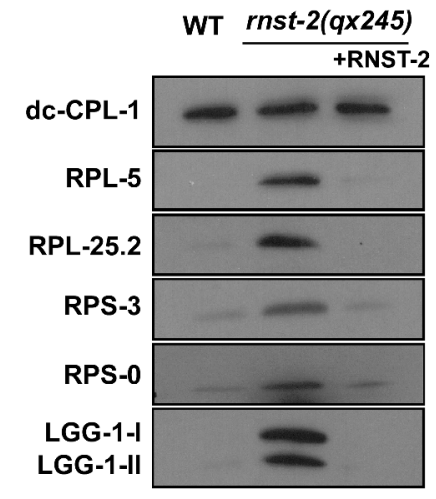

D

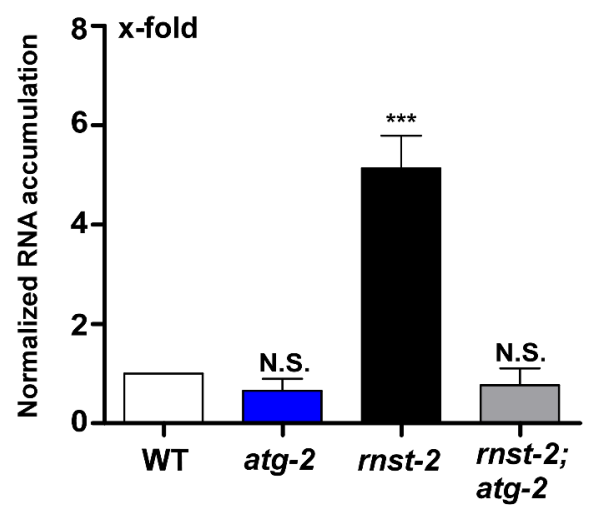

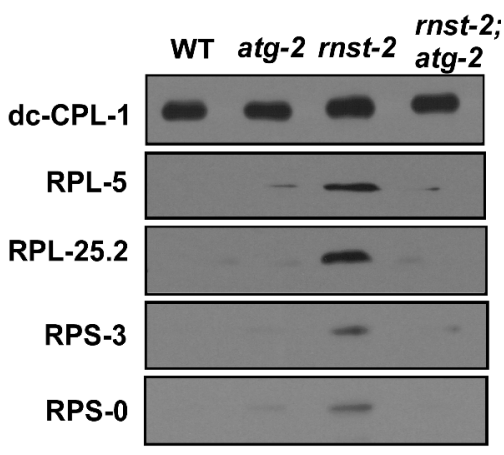

LAAT-1::GFP
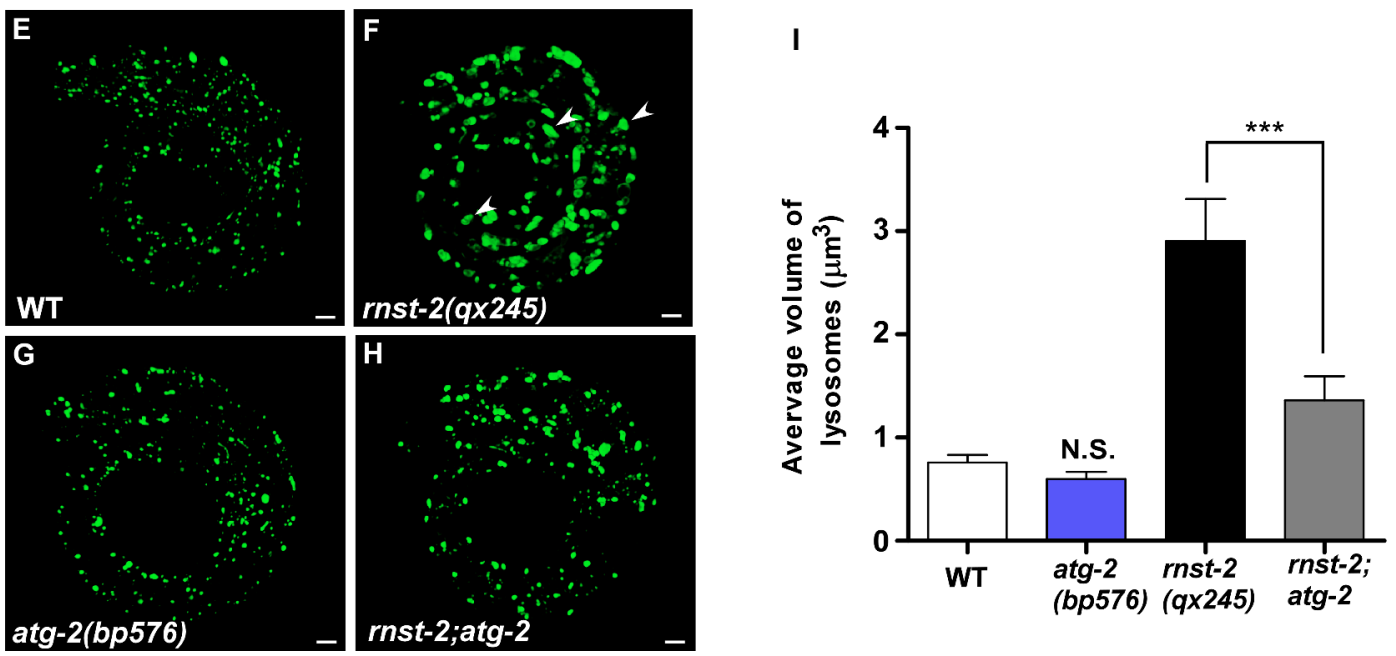

Figure 3. Loss of RNST-2 causes accumulation of rRNA and ribosomal proteins in lysosomes in an autophagy-dependent manner. (A, C) RNA purified from lysosomes in the indicated strains was examined by agarose gel electrophoresis. Full processing of the lysosomal cathepsin CPL-1 (dc-CPL-1) was used to normalize the amount of lysosomes in each strain. The total extracted RNA was quantified and normalized to 1-fold in wild type (A, C, right panel). Abundant $26 \mathrm{~S}$ and $18 \mathrm{~S}$ rRNA was observed in lysosomes of rnst-2(qx245) mutants. At least three independent experiments were performed and Figure 3 continued on next page 
Figure 3 continued

data are shown as mean \pm SD. (B, D) Accumulation of ribosomal proteins (large subunit: RPL-5, RPL-25.2; small subunit: RPS-3 and RPS-0) and LGG-1 in lysosomes was examined by western blot analysis in the indicated strains. Full processing of the lysosomal cathepsin CPL-1 (dc-CPL-1) was used to normalize the amount of lysosomes in each strain. (E-H) 3D reconstitution of the fluorescence images in 10-15 z-series $(0.5 \mu \mathrm{m} / \mathrm{section})$ in $\mathrm{L} 1$ larvae of the indicated strains expressing LAAT-1::GFP. Enlarged lysosomes (arrowheads) were observed in rnst-2(qx245). (I) Quantification of the average volume of lysosomes in the strains shown in (E-H). At least 10 worms were scored in each strain and data are shown as mean \pm SD. In (A, C, I), one-way ANOVA with Tukey's post hoc test was performed to compare all other datasets with wild type or datasets that are linked by lines (I). ${ }^{\star * *} \mathrm{p}<0.0001, \mathrm{~N} . \mathrm{S} .:$ no significance.

DOI: https://doi.org/10.7554/eLife.36588.008

The following source data and figure supplements are available for figure 3 :

Source data 1. Figure 3 numerical data.

DOI: https://doi.org/10.7554/eLife.36588.011

Source data 2. Figure 3-figure supplement 1 numerical data.

DOI: https://doi.org/10.7554/eLife.36588.012

Source data 3. Figure 3-figure supplement 2 numerical data.

DOI: https://doi.org/10.7554/eLife.36588.013

Figure supplement 1. Lysosomal accumulation of rRNA and ribosomal proteins in rnst-2 is suppressed by blocking autophagy.

DOI: https://doi.org/10.7554/eLife.36588.009

Figure supplement 2. Loss of RNST-2 does not affect degradation of endocytic and phagocytic cargos.

functions disrupt progression from phagophores to complete autophagosomes (Tian et al., 2010; Lu et al., 2011). We found that mutation of atg-2 or epg-6 completely suppressed lysosomal accumulation of rRNA and ribosomal proteins in rnst-2(qx245) mutants (Figure 3C,D and Figure 3-figure supplement 1E,F). Moreover, lysosome volume, which was greatly increased in rnst-2(qx245), was reduced significantly in rnst-2;atg-2 double mutants (Figure 3E-I). Loss of EPG-6 or LGG-1, the C. elegans homolog of Atg8/LC3, also led to greatly reduced lysosome volume in rnst-2 (Figure 3figure supplement 1G-M). Altogether, these data suggest that rRNA and ribosomal proteins are delivered to lysosomes through autophagy and defects in their degradation lead to enlargement of lysosomes in rnst-2 mutants.

\section{Loss of RNST-2 does not affect endocytic and phagocytic cargo degradation but partially impairs autophagy}

rnst-2 mutants accumulate ribosomal RNA and proteins that are delivered to lysosomes by autophagy. We next examined whether loss of RNST-2 also affects degradation of endocytic and phagocytic cargos. Cell surface protein CAV-1 and yolk lipoprotein VIT-2 are delivered to lysosomes through the endocytic pathway and are degraded shortly after fertilization and during embryogenesis, respectively (Sato et al., 2006; Grant and Hirsh, 1999). In rnst-2(qx245) embryos, both VIT-2:: GFP and CAV-1::GFP were properly degraded as in wild type (Figure 3-figure supplement 2A$H^{\prime}$ ). Moreover, rnst-2(qx245) mutants contained similar numbers of embryonic and germ cell corpses as in wild type, suggesting that phagocytosis and degradation of apoptotic cells is unaffected (Figure 3-figure supplement $21, J)$. These data suggest that lysosomal degradation of endocytic and phagocytic cargos is not affected in rnst-2(If) mutants. rnst-2(If) lysosomes contained high levels of LGG-1, which associates with autophagosomes and their precursors (Figure 3B). This lysosomal accumulation of LGG-1 is consistent with defects in degrading autophagic cargos (Tian et al., 2010). We next examined whether the autophagy process is affected in rnst-2 mutants. The PGL granule component PGL-3 is removed in soma by selective autophagy during embryogenesis, which requires the bridging molecule SEPA-1 (Zhang et al., 2009). PGL-3 and SEPA-1 puncta persisted in autophagy-defective mutants such as atg-2 (Figure 4-figure supplement 1C, $C^{\prime}, F_{\text {, }}$ ) (Zhang et al., 2009), but were removed in both wild-type and rnst-2 embryos, suggesting that autophagic clearance of PGL granules is unaffected in rnst-2 mutants (Figure 4-figure supplement 1A-B', D-E'). SOST-1 is the $C$. elegans p62 homolog that associates with various protein aggregates and is removed by autophagy (Tian et al., 2010). SQST-1 puncta were cleared in wild-type embryos, present in late-staged rnst-2 mutant embryos, and persisted at both early and late stages in atg-2 embryos (Figure 4A-I' and Figure 4-figure supplement 1G-I'). Similarly, LGG-1, which associates 


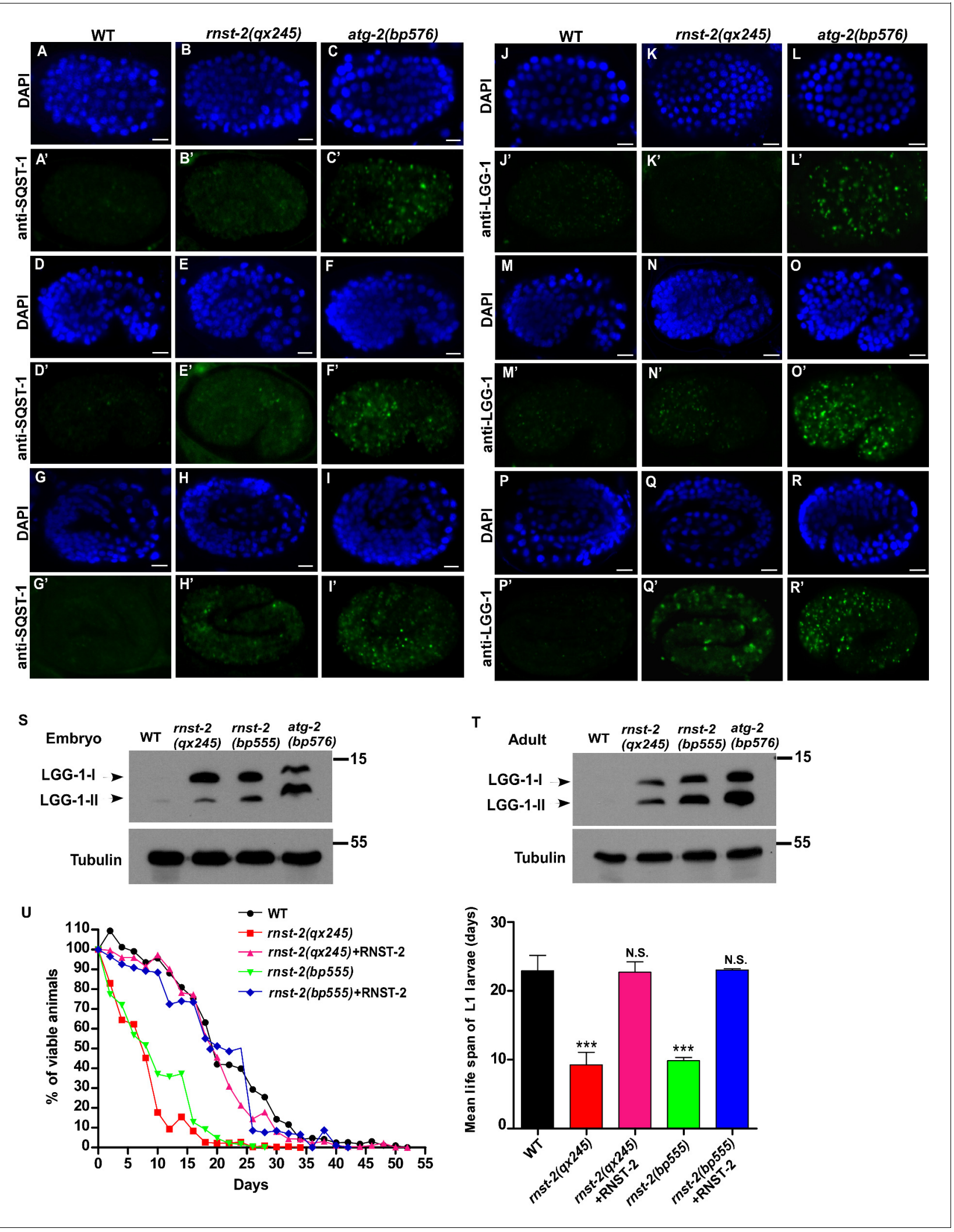

Figure 4. Autophagy is partially impaired in rnst-2 mutants. (A-R') Confocal fluorescence images of embryos in wild type (WT), rnst-2(qx245) and atg-2 (bp576) at 200 cell $\left(A-C^{\prime}, J-L^{\prime \prime}\right)$, comma (D-F', M-O') and 4-fold (G-I', P-R') stages stained by anti-SQST-1 (A-I') or anti-LGG-1 antibodies (J-R'). DAPI staining shows nuclei in each embryo. Scale bars: $5 \mu \mathrm{m}$. (S, T) Western blot analysis of LGG-1-I and LGG-1-II (lipid-conjugated form) in wild-type, rnst-2 (qx245), rnst-2(bp555) and atg-2(bp576) at the embryonic (S) and adult stages (day 3 of adulthood) (T). (U) The survival of L1 larvae in the absence of Figure 4 continued on next page 
Figure 4 continued

food was quantified in the indicated strains. At least 200 animals were scored at each time point in each strain. three independent experiments were performed and the mean lifespan of L1 larvae in the absence of food was quantified (right panel). The data are shown as mean \pm SD. One-way ANOVA with Tukey's post hoc test was performed to compare mutant datasets with wild type. ${ }^{\star \star \star} p<0.0001$, N.S., no significance.

DOl: https://doi.org/10.7554/eLife.36588.014

The following source data and figure supplements are available for figure 4:

Source data 1. Figure 4 numerical data.

DOl: https://doi.org/10.7554/eLife.36588.017

Figure supplement 1. Autophagic clearance of PGL granule is not affected in rnst-2 mutants.

DOI: https://doi.org/10.7554/eLife.36588.015

Figure supplement 2. GFP::ATG-18 is diffuse in the cytoplasm of wild-type and rnst-2 mutant embryos.

DOI: https://doi.org/10.7554/eLife.36588.016

with autophagic structures and is a substrate of autophagy, was present in atg-2 embryos at both early and late stages, but accumulated only in late-staged embryos in rnst-2 mutants (Figure 4J-R' and Figure 4-figure supplement 1J-L'). In addition, GFP::ATG-18, the Ptdlns3P-binding protein that associates with early autophagic structures (Lu et al., 2011), was diffuse in the cytoplasm in both wild type and rnst-2(lf), suggesting that autophagosome formation is not blocked (Figure 4figure supplement 2). Altogether, these data suggest that the autophagy process is partially impaired or delayed in rnst-2(If), causing accumulation of SQST-1 and LGG-1 in late-staged embryos. Consistent with this, rnst-2 mutants accumulated both LGG-1-I and LGG-1-II (lipid-conjugated form of LGG-1) at embryonic and adult stages (Figure $4 S$ and T). Moreover, loss of rnst-2 significantly shortened the lifespan of the L1 larvae in the absence of food (Figure 4U), a process that requires autophagy activity (Kang et al., 2007).

\section{rnst-2 mutants are defective in embryogenesis and larval development, and are short-lived}

rnst-2 mutants are viable but grow slowly. Both rnst-2(qx245) and rnst-2(bp555) were retarded in embryogenesis and exhibited 20-30\% embryonic lethality (Figure 5A and B). Moreover, approximately $50 \%$ of rnst-2(qx245) and rnst-2(bp555) embryos that hatched were arrested during larval development, and this arrest was rescued by expression of RNST-2 (Figure $5 \mathrm{C}$ ). These data indicate that loss of rnst-2 severely affects embryonic and larval development. In addition to affecting development, rnst-2 mutants are short-lived compared with wild type (Figure 5D and E). To further investigate the effect of rnst-2(If) on lifespan, we examined whether loss of rnst-2 affects the lifespan of long-lived mutants. Reducing insulin signaling extends the lifespan in C. elegans (Murphy and Hu, 2013). Worms that carry a loss-of-function mutation in the insulin receptor DAF-2 live twice as long as wild-type worms (Figure 5D and E) (Kenyon et al., 1993). We found that loss of rnst-2 significantly reduced the lifespan of daf-2(If) worms to the wild-type level (Figure 5D and E). Moreover, loss of rnst-2 also reduced the lifespan of glp-1(e2144), which affects germline stem cells and thus extends lifespan (Figure 5F and G) (Arantes-Oliveira et al., 2002). These data suggest that RNST-2 function is important for maintaining normal lifespan and for the lifespan extension in daf- 2 and glp-1.

\section{Simultaneous loss of rnst-2 and de novo synthesis of pyrimidines leads to synthetic embryonic lethality}

RNST-2 is an endoribonuclease that degrades RNA in lysosomes. We suspected that defective RNA degradation in rnst-2(lf) mutants affects generation and recycling of RNA catabolites, which are important for animal development. Pyrimidine and purine nucleotides are essential components of RNA. They are produced through both de novo and salvage pathways and are building blocks for the synthesis of RNA, DNA, phospholipids and nucleotide sugars (Huang and Graves, 2003). As purine metabolic pathways are not well understood in $C$. elegans and the key enzyme involved in purine biosynthesis is not clearly identified, we focused on the pyrimidine pathway. PYR-1/CAD and UMPS-1/UMPS are two key enzymes required for the de novo synthesis of UMP, the precursor for other pyrimidine nucleotides (Merry et al., 2014; Franks et al., 2006; Huang and Graves, 2003). pyr-1(cu8) and umps-1(mn160) single mutants exhibited $50 \%$ and $25 \%$ embryonic lethality, 


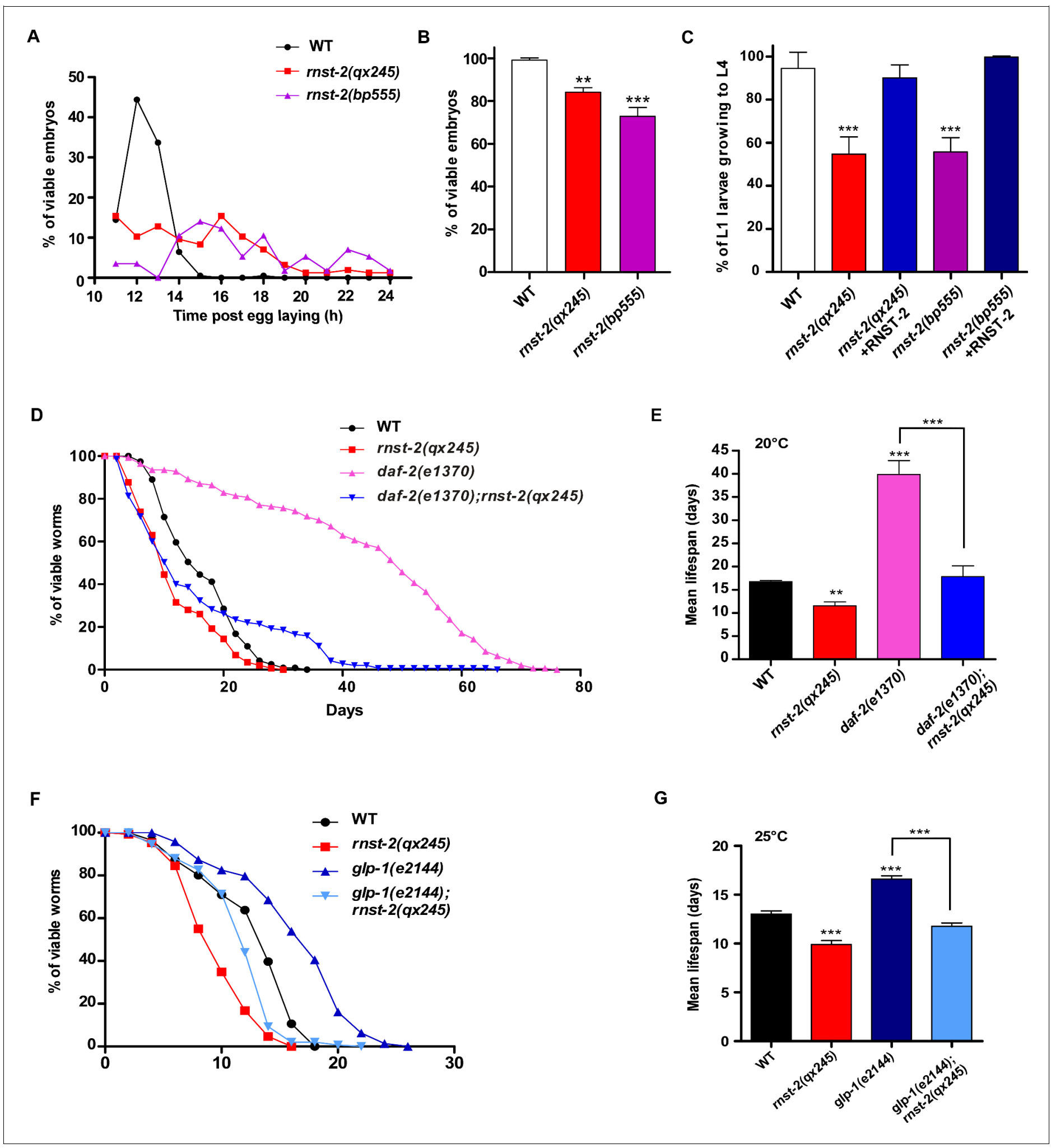

Figure 5. rnst-2 mutants are defective in embryogenesis and larval development, and are short-lived. (A-C) Embryonic and larval development was examined in wild type, rnst-2(qx245) and rnst-2(bp555). At least 150 embryos and 100 larvae were examined in each strain and at least three independent experiments were performed. (D-G) Lifespan analyses were performed in the indicated strains. More than 100 worms were examined in each strain and three independent experiments were performed. The mean lifespan in the indicated strains was quantified and is shown in (E, G). Data are shown as mean \pm SD. One-way ANOVA with Tukey's post hoc test was performed to compare datasets with wild type or datasets that are linked by lines. ${ }^{*} p<0.05,{ }^{* *} p<0.001,{ }^{* * *} p<0.0001$.

Figure 5 continued on next page 
Figure 5 continued

DOI: https://doi.org/10.7554/eLife.36588.018

The following source data is available for figure 5:

Source data 1. Figure 5 numerical data.

respectively, indicating that pyrimidine biosynthesis is important for embryogenesis (Figure 6A and $B)$. We found that loss of rnst- 2 and pyr- 1 or rnst-2 and umps- 1 led to almost $100 \%$ embryonic lethality (Figure 6A,B and Figure 6-figure supplement 1A,B). By contrast, loss of the lysosomal amino acid transporter LAAT-1, which blocks transport of lysine and arginine out of lysosomes, did not cause increased embryonic lethality in pyr-1 or umps-1 mutants (Figure 6A and B) (Liu et al., 2012). Moreover, loss of LMP-1, the lysosomal membrane protein homologous to human LAMP1, did not affect embryonic and larval development, and had no effect on the embryonic viability in pyr-1 or umps-1 (Figure 6-figure supplement 1C-E). These data suggest that loss of RNST-2 function, but not a general defect of lysosomes, leads to the synthetic embryonic lethality in pyr-1 or umps-1 mutants. Similar to rnst-2(If), the pyr-1(cu8) mutation also caused a significantly shortened lifespan in daf-2(lf) worms, whereas laat-1(qx42) was less effective in reducing the daf-2(If) lifespan (Figure 6figure supplement $1 \mathrm{~F}-\mathrm{I})$. These data suggest that maintenance of pyrimidine homeostasis is important for extended lifespan in daf-2(lf).

To further test whether lysosomal degradation of rRNA by RNST-2 is important in providing pyrimidines during embryonic development, we performed pyrimidine supplement experiments. External supplement of uridine had no effect on embryogenesis in wild type, but efficiently suppressed the synthetic embryonic lethality in pyr-1;rnst-2 double mutants (Figure 6C). The embryonic lethality in umps-1;rnst-2 was partially relieved by uridine supplement, consistent with the idea that UMPS-1 acts in both de novo and salvage pathways to synthesize UMP (Figure 6D) (Merry et al., 2014). We found that cytidine supplement caused reduced viability of wild-type embryos, but it partially suppressed the synthetic embryonic lethality in pyr-1;rnst-2 and umps-1;rnst-2 double mutants, albeit to a lesser extent than uridine supplements (Figure 6E and F). These data suggest that RNA degradation by RNST-2 in lysosomes is important in maintaining pyrimidine homeostasis during embryogenesis. We found that the autophagy-defective mutations lgg-1(bp500), atg-2(bp576), atg-18(gk378) and atg-9(bp564) partially affected embryogenesis and caused synthetic embryonic lethality in pyr-1 (RNAi) and umps-1(RNAi) worms, consistent with the role of autophagy in delivering RNA to lysosomes (Figure 6-figure supplement 1A,B). Supplements of uridine or cytidine did not obviously improve the embryonic viability of rnst-2(qx245) single mutants or in autophagy-defective mutants (Figure $6 C-F$ and Figure 6-figure supplement $1 C, D$ ), suggesting that a general autophagy defect may contribute to the partial embryonic lethality in these worms.

\section{Discussion}

\section{RNST-2 degrades ribosomal RNA delivered by autophagy in lysosomes}

Here we identified C. elegans RNST-2, a T2 family endoribonuclease, as a key enzyme that degrades ribosomal RNA in lysosomes. RNST-2 localizes to lysosomes and loss of its function causes rRNA accumulation in enlarged lysosomes in an autophagy-dependent manner. Thus, RNST-2 degrades rRNA delivered by autophagy in lysosomes, which is consistent with the function of Ryn1 and RNS2, the yeast and Arabidopsis thaliana T2 family endoribonucleases, respectively (Huang et al., 2015; Floyd et al., 2015). Loss of zebrafish rnaset2 results in accumulation of undigested rRNA in lysosomes of neurons (Haud et al., 2011), while expression of human RNASET2 in worms efficiently rescued the lysosome phenotype in rnst-2 mutants (Figure 1-figure supplement 2E,I). Thus, T2 family endoribonuclease acts as the key enzyme to degrade ribosomal RNA in lysosomes in diverse species throughout evolution. The rnst-2 lysosomes appear to accumulate intact $26 \mathrm{~S}$ and $18 \mathrm{~S}$ rRNA, suggesting that mature ribosomes are targeted for degradation. In addition to rRNA, rnst-2 lysosomes also contain high levels of ribosomal proteins, suggesting that rRNA degradation may facilitate destruction and further digestion of ribosomes. Our data suggest that the autophagy process is partially 


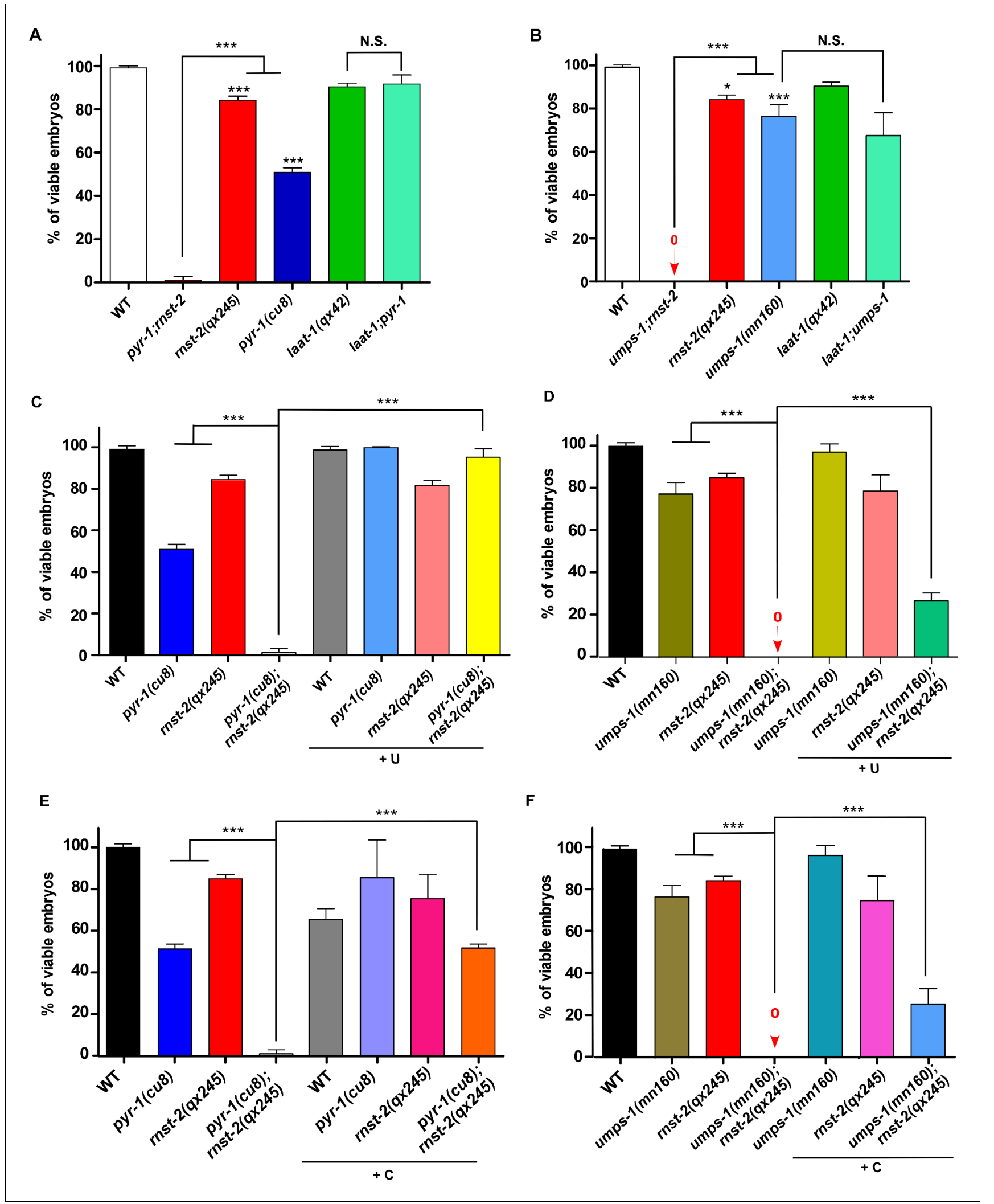

Figure 6. RNST-2 maintains pyrimidine availability for embryonic development. The percentage of viable embryos was scored in the indicated strains without (A, B) or with uridine (C, D) or cytidine supplementation (E, F). At least 150 embryos were examined in each strain and three independent experiments were performed. Data are shown as mean \pm SD. One-way ANOVA with Tukey's post hoc test was performed to compare all other datasets with wild type or datasets that are linked by lines. ${ }^{\star} p<0.05,{ }^{* \star} p<0.001,{ }^{* \star *} p<0.0001$, N.S.: no significance.

Figure 6 continued on next page 
Figure 6 continued

DOI: https://doi.org/10.7554/eLife.36588.020

The following source data and figure supplements are available for figure 6:

Source data 1. Figure 6 numerical data.

DOI: https://doi.org/10.7554/eLife.36588.023

Source data 2. Figure 6-figure supplement 1 numerical data.

DOl: https://doi.org/10.7554/eLife.36588.024

Source data 3. Figure 6-figure supplement 2 numerical data.

DOI: https://doi.org/10.7554/eLife.36588.025

Figure supplement 1. Loss of RNST-2 function but not a general lysosomal defect leads to synthetic embryonic lethality in pyr-1 and umps-1 mutants. DOI: https://doi.org/10.7554/eLife.36588.021

Figure supplement 2. Autophagy is important for maintaining pyrimidine availability during embryonic development. DOI: https://doi.org/10.7554/eLife.36588.022

impaired in rnst-2 mutants. We suspect that gradual buildup of undigested rRNA and ribosomal proteins in lysosomes leads to impaired autophagy kinetics and thus reduction in autophagic flux. Consistent with this, dysregulation of autophagy has been commonly found in lysosomal storage disorders characterized by the accumulation of undegraded metabolites in lysosomes (Seranova et al., 2017).

\section{Ribosomal RNA degradation through the autophagy-lysosome pathway is important in maintaining nucleotide homeostasis essential for animal development}

Bulk or selective degradation of ribosomes via the autophagy-lysosome pathway is important for cell survival under nutrient deprivation conditions, but whether it occurs under normal conditions and is important for animal physiology remains unclear. Here, we found that loss of RNST-2 function affects degradation of ribosomal RNA and proteins, and causes severe developmental defects, suggesting that ribosome degradation occurs under normal growth conditions and is important for animal development. Importantly, simultaneous loss of RNST-2 or autophagy and the de novo synthesis of pyrimidines causes complete embryonic lethality, and this synthetic lethality can be suppressed by exogenous supply of uridine or cytidine. This indicates that rRNA turnover through the autophagylysosome pathway plays an important role in maintaining nucleotide homeostasis during development. We have attempted to measure the nucleoside levels by LC/MS in rnst-2;pyr-1(RNAi) embryos, and observed a reduction in cytidine but not guanosine (data not shown). Given that the nucleoside levels were measured in embryonic lysates prepared from unhealthy embryos with an intact purine synthesis pathway but containing heterogeneous tissues and both intracellular and extracellular nucleosides, the results may not reflect the situation in key tissues that cause the phenotype.

The nucleosides or nucleobases derived from lysosomal rRNA turnover may be re-utilized through the pyrimidine salvage pathway to provide precursors to multiple metabolic pathways essential for development (Huang et al., 2015; Huang and Graves, 2003). In rnst-2 embryos, lysosome enlargement was not observed at the early phase of embryogenesis (before comma) when cell proliferation and organogenesis occur, but was very obvious after the 2-fold stage, during which extensive morphogenesis occurs and cell proliferation almost ceases (Figure 1-figure supplement 10) (Riddle et al., 1997). It is possible that excessive ribosomes are removed at the late phase of embryogenesis to cope with the lower demand for protein synthesis and the high levels of energy that are required for morphogenesis and hatching. Although supplements of uridine or cytidine significantly reduced the embryonic lethality in rnst-2;pyr-1 double mutants, it did not obviously improve the embryonic viability of rnst-2(qx245) single mutants, suggesting that the developmental phenotype may be attributed to defects in both general autophagy and nucleotide supply.

In addition to late embryonic and early larval stages, enlarged lysosomes are also present in rnst2 adults, and the rnst-2 mutation reduces the lifespan of both wild-type and long-lived daf- 2 and glp-1 worms. This suggests that lysosomal degradation of ribosomes also occurs during adulthood and may contribute to longevity. Lysosome-dependent ribosome turnover may help to clear defective ribosomes generated during aging and/or contribute to downregulation of protein translation. It is reported recently that NUFIP1 serves as a receptor for the selective autophagy of ribosomes in 
mammalian cells under nutrient starvation conditions to supply nucleosides required for cell survival during starvation (Wyant et al., 2018). Here we found that ribosome degradation through the autophagy-lysosome pathway occurs under normal growth conditions and is important for development and longevity. Whether ribosomes are recognized and removed through selective or bulk autophagy during development and aging requires future investigations.

Our study reveals the essential role of autophagy-dependent ribosome degradation in animal development, which may be conserved through evolution as both the autophagy machinery and T2 family endoribonucleases are highly similar from worms to humans. Loss-of-function mutations in human RNASET2 lead to familial cystic leukoencephalopathy, which is considered as a lysosome storage disease, but how lysosomal rRNA accumulation leads to neuronal disease is unclear (Henneke et al., 2009; Haud et al., 2011). Our finding that loss of rnst-2 affects nucleotide homeostasis and partially impairs autophagy may provide further insights into the disease pathogenesis.

\section{Materials and methods}

Key resources table

\begin{tabular}{|c|c|c|c|c|}
\hline $\begin{array}{l}\text { Reagent type (species) } \\
\text { or resource }\end{array}$ & Designation & Source or reference & Identifiers & $\begin{array}{l}\text { Additional } \\
\text { information }\end{array}$ \\
\hline \multirow[t]{5}{*}{$\begin{array}{l}\text { Gene } \\
\text { (C. elegans) }\end{array}$} & rnst-2 & & WBGene00019624 & $\begin{array}{l}\text { Other name: } \\
\text { CELE_K10C9.3 }\end{array}$ \\
\hline & rpl-5 & & WBGene00004416 & $\begin{array}{l}\text { Other name: } \\
\text { CELE_F54C9.5 }\end{array}$ \\
\hline & rpl-25.2 & & WBGene00004439 & $\begin{array}{l}\text { Other name: } \\
\text { CELE_F52B5.6 }\end{array}$ \\
\hline & rps-3 & & WBGene00004472 & $\begin{array}{l}\text { Other name: } \\
\text { CELE_C23G10.3 }\end{array}$ \\
\hline & rps-0 & & WBGene00004469 & $\begin{array}{l}\text { Other name: } \\
\text { CELE_B0393.1 }\end{array}$ \\
\hline Gene (human) & rnaset2 & $\begin{array}{l}\text { National Center for } \\
\text { Biotechnology Information }\end{array}$ & Gene ID: 8635 & \\
\hline \multirow[t]{17}{*}{$\begin{array}{l}\text { Strain } \\
\text { (C. elegans) }\end{array}$} & N2 & CGC & $\begin{array}{l}\text { RRID:WB-STRAIN:N2 } \\
\text { _(ancestral) }\end{array}$ & wild type (Bristol) \\
\hline & XW1624 & DOI: 10.1126/science.1220281 & & laat-1(qx42) \\
\hline & XW5331 & DOI: 10.1016/j.cell.2010.04.034 & & $\operatorname{lgg}-1(b p 500)$ \\
\hline & OK286 & DOI: 10.1042/BJ20131085 & RRID:WB-STRAIN:OK286 & pyr-1(cu8) \\
\hline & HZ1690 & DOI 10.1016/j.devcel.2011.06.024 & RRID:WB-STRAIN:HZ1690 & epg-6(bp242) \\
\hline & SP507 & DOI: 10.1042/BJ20131085 & RRID:WB-STRAIN:SP507 & umps-1(mn160) \\
\hline & CF1041 & DOI: 10.1126/science.1139952 & & daf-2(e1370) \\
\hline & HZ1687 & DOI: 10.1083/jcb.201209098 & RRID:WB-STRAIN:HZ1687 & atg-9(bp564) \\
\hline & VC893 & DOI: 10.1016/j.cell.2010.04.034 & RRID:WB-STRAIN:VC893 & atg-18(gk378) \\
\hline & XW10781 & this paper & & rnst-2(qx245) \\
\hline & XW15104 & this paper & & rnst-2(bp555) \\
\hline & HZ1683 & DOI 10.1016/j.devcel.2011.06.024 & RRID:WB-STRAIN:HZ1683 & atg-2(bp576) \\
\hline & CF1903 & CGC & RRID:WB-STRAIN:CF1903 & glp-1(e2144) \\
\hline & XW5097 & RRID:WB-STRAIN:PD4482 & & Imp-1(nr2045) \\
\hline & XW7251 & DOI: 10.1126/science.1220281 & & $\begin{array}{l}\text { qxIs354 } \\
\left(P_{\text {ced-1 }} \text { LAAT-1::GFP }\right)\end{array}$ \\
\hline & XW5399 & DOI: 10.1126/science.1220281 & & $\begin{array}{l}\text { qxIs257 } \\
\left(P_{\text {ced-1 }} \text { NUC-1::CHERRY }\right)\end{array}$ \\
\hline & XW8056 & DOI: 10.1083/jcb.201602090 & & $\begin{array}{l}\text { qxIs430 } \\
\left(P_{\text {scav }-3} \text { SCAV-3::GFP) }\right.\end{array}$ \\
\hline
\end{tabular}

\footnotetext{
Continued on next page
} 
Continued

\begin{tabular}{|c|c|c|c|c|}
\hline $\begin{array}{l}\text { Reagent type (species) } \\
\text { or resource }\end{array}$ & Designation & Source or reference & Identifiers & $\begin{array}{l}\text { Additional } \\
\text { information }\end{array}$ \\
\hline & XW10197 & DOI: 10.1083/jcb.201602090 & & $\begin{array}{l}\text { qx/s468 } \\
\left(P_{\text {myo-3 }} \text { LAAT-1::GFP }\right)\end{array}$ \\
\hline & XW642 & DOI: 10.1091/mbc.10.12.4311 & & $\begin{array}{l}\text { bls1 } \\
\left(P_{\text {vit-2VIT-2::GFP })}\right.\end{array}$ \\
\hline & RT688 & DOI: 10.1126/science.1220281 & & $\begin{array}{l}\text { pwls281 } \\
\left(P_{\text {pie- } 1} \text { CAV-1::GFP }\right)\end{array}$ \\
\hline & XW8293 & DOI: 10.15252/embr.201438618 & & $\begin{array}{l}\text { qxEx4098 } \\
\left(P_{\text {ced-1 }} \text { GFP:ATG-18) }\right.\end{array}$ \\
\hline & XW12615 & this paper & & $\begin{array}{l}\text { qxIs544 } \\
\left(P_{\text {rnst-2RNST-2::CHERRY })} \text { RNST }\right.\end{array}$ \\
\hline & XW13567 & this paper & & $\begin{array}{l}\text { qxEx6614 } \\
\left(P_{\text {rnst-2 } 2 \text { RNST-2(H118A) }:: \text { CHERRY })}\right.\end{array}$ \\
\hline & XW8783 & this paper & & $\begin{array}{l}\text { qxEx4279 } \\
\left(P_{\text {myo-3 }} \text { LAAT-1::GFP }\right)\end{array}$ \\
\hline & XW17778 & this paper & & $\begin{array}{l}\text { qXEx8302 } \\
\left(P_{\text {rnst-2RNASET2-CHERRY })}\right.\end{array}$ \\
\hline Antibody & $\begin{array}{l}\text { anti-RPL-5 } \\
\text { (rat polyclonal) }\end{array}$ & this paper & & WB(1:300) \\
\hline & $\begin{array}{l}\text { anti-RPL-25.2 } \\
\text { (rat polyclonal) }\end{array}$ & this paper & & WB(1:300) \\
\hline & $\begin{array}{l}\text { anti-RPS-0 } \\
\text { (rat polyclonal) }\end{array}$ & this paper & & WB(1:1000) \\
\hline & $\begin{array}{l}\text { anti-RPS-3 } \\
\text { (rat polyclonal) }\end{array}$ & this paper & & WB(1:1000) \\
\hline & $\begin{array}{l}\text { anti-CPL-1 } \\
\text { (rat polyclonal) }\end{array}$ & DOI: 10.1126/science.1220281 & & WB(1:500) \\
\hline & $\begin{array}{l}\text { anti-LGG-1 } \\
\text { (rat polyclonal) }\end{array}$ & DOI: 10.1016/j.cell.2010.04.034 & & $\begin{array}{l}\text { WB(1:1000); } \\
\text { Immunostaining }(1: 1000)\end{array}$ \\
\hline & $\begin{array}{l}\text { anti-alpha-Tubulin } \\
\text { (mouse monoclonal) }\end{array}$ & Sigma-Aldrich (Missouri, USA) & $\begin{array}{l}\text { Cat \#T5168; } \\
\text { RRID:AB_477579 }\end{array}$ & WB(1:10000) \\
\hline & $\begin{array}{l}\text { anti-SQST-1 } \\
\text { (rat polyclonal) }\end{array}$ & DOI: 10.1016/j.cell.2010.04.034 & & $\begin{array}{l}\text { Immunostaining } \\
(1: 1000)\end{array}$ \\
\hline & $\begin{array}{l}\text { anti-PGL-3 } \\
\text { (rat polyclonal) }\end{array}$ & DOI: 10.1016/j.cell.2010.04.034 & & $\begin{array}{l}\text { Immunostaining } \\
(1: 1000)\end{array}$ \\
\hline & $\begin{array}{l}\text { anti-SEPA-1 } \\
\text { (rabbit polyclonal) }\end{array}$ & DOI: 10.1016/j.cell.2010.04.034 & & $\begin{array}{l}\text { Immunostaining } \\
(1: 1000)\end{array}$ \\
\hline & $\begin{array}{l}\text { anti-HSP-60 } \\
\text { (mouse polyclonal) }\end{array}$ & DOI: 10.1126/science.1220281 & & WB(1:1000) \\
\hline & $\begin{array}{l}\text { anti-HEL-1 } \\
\text { (rabbit polyclonal) }\end{array}$ & DOI: 10.1126/science.1220281 & & WB(1:500) \\
\hline & $\begin{array}{l}\text { anti-RME-1 } \\
\text { (mouse polyclonal) }\end{array}$ & DOI: 10.1126/science.1220281 & & WB(1:1000) \\
\hline $\begin{array}{l}\text { Plasmids for generating } \\
\text { transgenic strains }\end{array}$ & $\begin{array}{l}\text { pPD49.26- } P_{\text {rnst-2RNST- }} \text { RP::CHERRY } \\
\text { 2:CHE }\end{array}$ & this paper & & $\begin{array}{l}\text { Cloning described in } \\
\text { 'Plasmid construction' }\end{array}$ \\
\hline & $\begin{array}{l}\text { pPD49.26-P } P_{\text {rnst-2 }} \\
\text { RNASET2::CHERRY }\end{array}$ & this paper & & $\begin{array}{l}\text { Cloning described in } \\
\text { 'Plasmid construction' }\end{array}$ \\
\hline & $\begin{array}{l}\text { PPD } 49.26-P_{\text {rnst-2 }} \\
\text { RNST-2(H118A)::CHERRY }\end{array}$ & this paper & & $\begin{array}{l}\text { Cloning described in } \\
\text { 'Plasmid construction' }\end{array}$ \\
\hline & $\begin{array}{l}\text { pPD49.26- } P_{\text {rnst-2 }} \text { RNST- } \\
\text { 2(cDNA)::CHERRY }\end{array}$ & this paper & & $\begin{array}{l}\text { Cloning described in } \\
\text { 'Plasmid construction' }\end{array}$ \\
\hline $\begin{array}{l}\text { Plasmids for protein } \\
\text { expression }\end{array}$ & pET-21b-rpl-25.2 & this paper & & $\begin{array}{l}\text { Cloning described in } \\
\text { 'Plasmid construction' }\end{array}$ \\
\hline
\end{tabular}

\section{Continued on next page}


Continued

\begin{tabular}{|c|c|c|c|c|}
\hline $\begin{array}{l}\text { Reagent type (species) } \\
\text { or resource }\end{array}$ & Designation & Source or reference & Identifiers & $\begin{array}{l}\text { Additional } \\
\text { information }\end{array}$ \\
\hline & pET-21b-rpl-5 & this paper & & $\begin{array}{l}\text { Cloning described in } \\
\text { 'Plasmid construction' }\end{array}$ \\
\hline & pET-21b-rps-0 & this paper & & $\begin{array}{l}\text { Cloning described in } \\
\text { 'Plasmid construction' }\end{array}$ \\
\hline & pET-21b-rps-3 & this paper & & $\begin{array}{l}\text { Cloning described in } \\
\text { 'Plasmid construction' }\end{array}$ \\
\hline \multirow[t]{2}{*}{ Commercial assay or kit } & Lysosome Isolation Kit & Sigma-Aldrich (Missouri, USA) & Cat \#LYSISO1 & \\
\hline & $\begin{array}{l}\text { RNeasy Plus Universal } \\
\text { Mini Kit }\end{array}$ & QIAGEN (Hilden, Germany) & Cat \#73404 & \\
\hline \multirow[t]{4}{*}{ Chemical compound, drug } & Uridine & Sigma-Aldrich (Missouri, USA) & Cat \#U3003 & \\
\hline & Cytidine & $\begin{array}{l}\text { Sigma-Aldrich } \\
\text { (Missouri, USA) }\end{array}$ & Cat \#C4654 & \\
\hline & DAPI & $\begin{array}{l}\text { Vector Laboratories } \\
\text { (California, USA) }\end{array}$ & $\begin{array}{l}\text { Cat \#H-1200; } \\
\text { RRID:AB_2336790 }\end{array}$ & \\
\hline & LysoTracker red & $\begin{array}{l}\text { Invitrogen } \\
\text { (Oregon, USA) }\end{array}$ & Cat \#L7528 & \\
\hline \multirow[t]{2}{*}{ Software, algorithm } & Velocity & $\begin{array}{l}\text { PerkinElmer } \\
\text { (Massachusetts, USA) }\end{array}$ & & \\
\hline & Zen & $\begin{array}{l}\text { Carl Zeiss } \\
\text { (Oberkochen, Germany) }\end{array}$ & RRID:SCR_01367 & \\
\hline
\end{tabular}

\section{C. elegans strains}

C. elegans strains were cultured and maintained at $20^{\circ} \mathrm{C}$ using standard protocols (Brenner, 1974). The N2 Bristol strain was used as the wild-type strain except in single nucleotide polymorphism (SNP) mapping, in which Hawaiian strain CB4856 was used. The strains used in this work are listed in the key resources table.

\section{Isolation, mapping, and cloning of rnst-2}

The qx245 and bp555 mutations were isolated from genetic screens for lysosome- and autophagydefective mutants, respectively. The qx245 mutation was mapped to the left side of LG V at the genetic map position -17 (Snp-pkP5076) by single nucleotide polymorphism (SNP) mapping. Transformation rescue experiments were performed and a fosmid clone in this region, WRM0636aH01, possessed rescue activity. Whole genome sequencing identified a point mutation in the coding sequence of K10C9.3 within WRM0636aH01. Expression of the long PCR fragment covering the open reading frame of K10C9.3 fully rescued the qx245 defect. The sequence of the K10C9.3 gene was determined in both qx245 and bp555 alleles and molecular lesions were identified. qx245 contained a G-to-A transition that results in a substitution of Gly 119 by Glu, while bp555 contained a C-to-T transition that generates a premature stop codon after Pro55. Both mutant alleles were backcrossed with N2 strain at least four times before further analyses.

\section{Lysotracker staining}

$\sim 50$ worms aged to day 3 of adulthood were soaked for $1.5 \mathrm{hr}$ in $80 \mu \mathrm{l}$ LysoTracker red solution (Invitrogen, Oregon, USA), which was diluted as 1:200 by M9. Worms were then transferred to NGM plates with fresh OP50 and recovered for $2 \mathrm{hr}$ before examination. All steps were performed in the dark.

\section{Quantification of lysosome number and volume}

Fluorescence images of embryos, larvae, and adults expressing LAAT-1::GFP or NUC-1: CHERRY in 10-15 z-series $(0.5 \mu \mathrm{m} /$ section) were captured by spinning-disk microscopy. Serial optical sections were reconstituted to 3D view and the number and volume of lysosomes were measured by Velocity software (PerkinElmer, Massachusetts, USA). At least 10 worms were quantified in each strain at each stage. 


\section{Microscopy and imaging analysis}

Differential interference contrast and fluorescence images were captured by an inverted confocal microscope (LSM880; Carl Zeiss, Oberkochen, Germany) with 488, 405 and 561 lasers and images were processed and viewed using Zen software (Carl Zeiss, Oberkochen, Germany). All images were taken at $20^{\circ} \mathrm{C}$.

\section{Generation of antibodies}

Full-length RPL-5, RPL-25.2, RPS-3 and RPS-0 ribosomal proteins tagged with six Histidine residues (RPL-5-His ${ }_{6}$, RPL-25.2-His ${ }_{6}$ RPS-3-His 6 , RPS-0-His $)_{6}$ were expressed in E. coli. The recombinant proteins were purified by Ni-NTA agarose beads and the eluted RPL-5-His 6 , RPS-3-His 6 and RPS-0-His 6 proteins were used to raise polyclonal antibodies in rat. For RPL-25.2-His 6 , a specific protein band was excised from the SDS-PAGE and used to generate polyclonal antibody in rat. The RPL-5 and RPS-0 polyclonal antibodies were further purified using RPL-5 or RPS-0 recombinant proteins. All polyclonal antibodies were generated in the Antibody Center at NIBS (National Institute of Biological Sciences, Beijing, China).

\section{Western blot analysis and immunostaining}

Mix-staged embryos of $C$. elegans were collected from aged adults by bleaching. Embryonic and worm lysates (day three adults) were obtained and analyzed by western blot using anti-LGG-1 antibodies and anti- $\alpha$-tubulin antibodies (Sigma-Aldrich, Missouri, USA).

For immunostaining, mix-staged embryos were fixed by ice-cold methanol and acetone on glass sheets treated by $1 \%$ poly-lysine. After blocking with $1 \%$ BSA and $10 \%$ fetal calf serum in phosphate buffered saline (PBS), the samples were incubated with anti-LGG-1(1:1000 dilution), anti-SQST-1 (1:1000 dilution), anti-SEPA-1 (1:1000 dilution) or anti-PGL-3 (1:1000 dilution) antibodies at $4^{\circ} \mathrm{C}$ overnight. The samples were washed three times in PBST (PBS $+0.2 \%$ Tween 20 ) and incubated with the secondary antibody (1:200 dilution) (Jackson ImmunoResearch, Pennsylvania, USA) for 80 min at room temperature in the dark. The samples were washed three times, then stained with DAPI (Vector Laboratories, California, USA) and visualized using a Zeiss LSM880 confocal microscope.

\section{Lysosome purification and examination of RNA accumulation}

Lysosomes were purified from adult worms by a Lysosome Isolation kit (LYSISO1; Sigma-Aldrich, Missouri, USA) as described previously with modifications (Liu et al., 2012). In brief, synchronized larvae one worms were cultured at $20^{\circ} \mathrm{C}$ to day 3 of adulthood and collected. Worm pellets were suspended in the extraction buffer supplied in the Lysosome Isolation kit and ruptured by glass beads with the FastPrep-24 Instrument (MP Biomedicals, Ohio, USA). The worm lysate was centrifuged at $14,000 \mathrm{rpm}$ to precipitate the crude lysosomes. The crude lysosomes were diluted in $19 \%$ Optiprep Density Gradient Medium Solution and further separated on a sucrose density gradient (from bottom to top: $27 \%, 19 \%, 16 \%, 8 \%$ ).

After centrifugation, lysosome enrichment was determined by the amount of processed CPL-1 (lysosomal cathepsin) in different fractions that contained the same amount of total proteins (from bottom to top: B1-4). The purity of the lysosome fraction (B3) was examined by antibodies that detect different intracellular organelles.

The purified lysosome fractions from different strains were examined for accumulation of ribosomal proteins by western blot and ribosomal RNAs by RNA purification (73404; QIAGEN, Hilden, Germany). The purified RNAs were separated and examined by agarose gel electrophoresis. At least three independent experiments were performed in each strain and average data are shown in Figure 3 and Figure 3-figure supplement 1.

\section{Examination of embryonic development, larval development and lifespan}

To examine embryonic development, $\sim 20$ young adult worms ( $24 \mathrm{hr}$ post L4) were placed on a NGM plate with OP50 for $2 \mathrm{hr}$. The worms were then removed and the eggs laid on the plate were followed. After $10 \mathrm{hr}$, newly hatched L1 worms were counted and transferred every hour until no new L1 worms hatched out. The percentage of eggs that hatched every hour was calculated to show the progress of embryonic development, and the total percentage of hatched L1 was quantified to 
determine level of embryonic lethality. More than 150 embryos were quantified in each strain. At least three independent experiments were performed in each strain and the average result from three experiments is shown in Figure 5, Figure 6, Figure 6-figure supplements 1 and 2. To analyze larval development, 100 L1 worms were collected. After 48 hr incubation, newly developed L4 worms were counted and transferred every hour until no live larvae were present on the plate. The total percentage of fully developed $L 4$ was quantified to determine the level of larval arrest. At least three independent experiments were performed in each strain and the average result from three experiments is shown in Figure 4-figure supplement $1 \mathrm{C}$ and Figure 6-figure supplement 1E. Lifespan assays were performed at $20^{\circ} \mathrm{C}$ or $25^{\circ} \mathrm{C}$ [glp-1(e2144) and the control strains] as described previously (Hansen et al., 2005). About 150 L4 worms (day 0) were picked to NGM plates with fresh OP50, 15 worms per plate. The surviving worms were counted every 2 days and were transferred to new plates to avoid interference from the progeny. The worms that crawled off the plate, exploded, bagged, or became contaminated were discarded. At least three independent experiments were performed for each strain. The representative survival curve is shown in Figure 5D and F, Figure 6figure supplement $1 F$ and $H$ and the mean lifespan from three experiments is shown in Figure $5 E$ and G, Figure 6-figure supplement $1 G$ and I.

\section{Quantification of L1 survival under starvation treatment}

Mix-staged embryos were collected and placed in M9 buffer, so that their growth could be synchronized to the larvae 1 (L1) stage. The L1 worms were transferred equally to 96-well plates, with about 200 larvae per well. The worms were transferred to NGM plates with fresh OP50 every 2 days and the surviving larvae were quantified. At least three independent experiments were performed for each strain. The representative survival curve is shown in Figure $4 \mathbf{U}$ (left panel) and the mean lifespan from three independent experiments is shown in Figure $4 U$ (right panel).

\section{RNAi}

The bacteria-feeding RNAi protocol was used as described before (Kamath and Ahringer, 2003). In pyr-1 RNAi (D2085.1; 3117-4214 nt) and umps-1 RNAi (T07C4.1; 274-1400 nt) experiments, 30 L1 or L2 worms (P0) were placed on the RNAi plates. Embryos of the F1 generation were collected and quantified for survival throughout embryonic development.

\section{Nucleotide supplementation}

Uridine and cytidine (Sigma-Aldrich, Missouri, USA) were dissolved in distilled water to a final concentration of $1 \mathrm{M}$ and this stock solution was stored at $-20^{\circ} \mathrm{C}$. The stock solution of uridine or cytidine was supplied to both NGM plates and OP50 culture spotted onto NGM plates as a 1:10 dilution. L4 larvae (P0) were placed on uridine- or cytidine-containing plates and cultured to the next generation (F1). The survival of the F2 embryos was quantified.

\section{Statistical analysis}

The standard deviation (SD) was used as y-axis error bars for bar charts plotted from the mean value of the data. Data derived from different genetic backgrounds were compared by Student's twotailed unpaired t test, one-way analysis of variance (ANOVA) with Tukey's post hoc test or two-way ANOVA with the Bonferroni post hoc test. Data were considered statistically different when $\mathrm{p}<0.05$. $p<0.05$ is indicated with single asterisks, $p<0.001$ with double asterisks and $p<0.0001$ with triple asterisks (0.001 in a two-way ANOVA analysis).

\section{Plasmid construction}

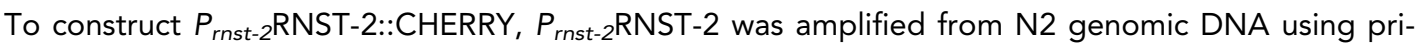
mers PDFZ482/PYBL29 and was ligated to pPD49.26-nCHERRY3 through the Nhe I/Nco I sites. To generate the $P_{\text {rnst-2 }}$ RNASET2::CHERRY reporter, the $2.1 \mathrm{~kb}$ promoter of rnst-2 was amplified from N2 genomic DNA using primers PYBL42/PYBL43 and cloned into pPD49.26-nCHERRY3 through the BamH I site. RNASET2 of Homo sapiens was amplified from a human cDNA library using the primers PDFZ487/PDFZ488 and cloned into $P_{\text {rnst-2 }}$ nCHERRY3 through the Nhe I/Nco I sites. $P_{\text {rnst-2 } 2 \text { RNST-2 }}$ $(\mathrm{H} 118 \mathrm{~A}):: \mathrm{CHERRY}$ was generated through PCR-based site-directed mutagenesis using the primers

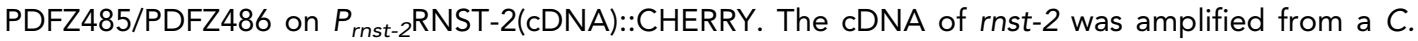


elegans cDNA library (Invitrogen, Oregon, USA) using primers PYBL32/PYBL41 and cloned into $P_{\text {rnst- }}$ ${ }_{2}$ nCHERRY3 through the Nhe I site. The RNST-2(H118A) fragment was digested from $P_{\text {rnst- } 2 \text { RNST-2 }}$

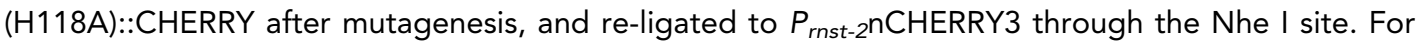
the protein expression vectors, the cDNAs of rpl-25.2, rps-3 and rps-0 were amplified from a C. elegans cDNA library (Invitrogen, Oregon, USA) using primers PYBL64/PYBL65, PYBL70/PYBL71 and PYBL67/PYBL68, respectively, and ligated to pET21b vector through the Nde I/Xho I sites. The cDNA of rpl-5 was amplified from a C. elegans cDNA library (Invitrogen, Oregon, USA) using the primers of PYBL99/PYBL101 and ligated to PET21b vector through the Nhe I/Xho I sites.

\section{Primers used for plasmid construction}

\begin{tabular}{|c|c|}
\hline Primer & Sequence $\left(5^{\prime}\right.$ to $\left.3^{\prime}\right)$ \\
\hline PDFZ482 & GCCCATGGCATTTCCAATATTTTTGATAGCGCTCC \\
\hline PYBL29 & GCGCTAGCCCGTGGGAGTAATGTTGC \\
\hline PYBL42 & GCGGATCCTTCTGGAAATCTTGCGTGAT \\
\hline PYBL43 & GCGGATCCGGCGACTACTGTAAACGA \\
\hline PDFZ487 & CGGCTAGCATGCGCCCTGCAGCCCTGCGCGG \\
\hline PDFZ488 & GCCCATGGCATGCTTGGTCTTTTTAGGTGGGG \\
\hline PDFZ485 & GAAACACGAGTATGATAAGGCCGGGACATGTGCTCAAAG \\
\hline PDFZ486 & CTTTGAGCACATGTCCCGGCCTTATCATACTCGTGTTTC \\
\hline PYBL32 & GCGCTAGCATGAAACTTCTCCTTCTTCTCT \\
\hline PYBL41 & GCGCTAGCATTTCCAATATTTTTTATAGCG \\
\hline PYBL64 & GCCATATGATGGCTCCGTCATCAAACAAAG \\
\hline PYBL65 & GCCTCGAGGATGAATCCGATCTTGTTGGCA \\
\hline PYBL70 & GCCATATGATGGCTGCCAATCAAAACGTGA \\
\hline PYBL71 & GCCTCGAGTTGAACTGGAGCAACTGGTTGA \\
\hline PYBL67 & GCCATATGATGTCAGGCGGTGCCGCTCATT \\
\hline PYBL68 & GCCTCGAGCCAGTTAGACTGGGTTGGAGCG \\
\hline PYBL99 & GCGCTAGCATGGGTCTCGTCAAGGTCATTA \\
\hline PYBL101 & GCCTCGAGCTCCTGTTGCTCCTTGAGTT \\
\hline
\end{tabular}

\section{Acknowledgements}

We thank Dr. Mengqiu Dong (National Institute of Biological Sciences) for antibodies and Dr. Isabel Hanson for editing services. Some strains were provided by the CGC, which is funded by NIH Office of Research Infrastructure Programs (P40OD010440). This work was supported by the Ministry of Science and Technology (2016YFA0500203), the National Science Foundation of China (3163001, 91754203) and the Strategic Priority Research Program of the Chinese Academy of Sciences (XDB19000000) to X W. The authors declare no competing financial interests.

\section{Additional information}

Funding

\begin{tabular}{ll} 
Funder & Author \\
\hline $\begin{array}{l}\text { Ministry of Science and Tech- } \\
\text { nology of the People's Repub- } \\
\text { lic of China }\end{array}$ & Xiaochen Wang \\
\hline $\begin{array}{l}\text { National Natural Science } \\
\text { Foundation of China }\end{array}$ & Xiaochen Wang \\
\hline Chinese Academy of Sciences & Xiaochen Wang \\
\hline
\end{tabular}

The funders had no role in study design, data collection and interpretation, or the decision to submit the work for publication.

Author contributions

Yubing Liu, Conceptualization, Formal analysis, Investigation, Visualization, Writing一original draft; Wei Zou, Li Wang, Yan Ma, Investigation, Visualization; Peiguo Yang, Investigation; Hong Zhang, 
Supervision, Writing-review and editing; Xiaochen Wang, Conceptualization, Supervision, Funding acquisition, Writing-original draft, Project administration

Author ORCIDs

Xiaochen Wang (iD http://orcid.org/0000-0002-4344-0925

Decision letter and Author response

Decision letter https://doi.org/10.7554/eLife.36588.029

Author response https://doi.org/10.7554/eLife.36588.030

\section{Additional files}

Supplementary files

- Transparent reporting form

DOI: https://doi.org/10.7554/eLife.36588.026

Data availability

All data generated or analyses during this study are included in the manuscript and supporting files.

\section{References}

Arantes-Oliveira N, Apfeld J, Dillin A, Kenyon C. 2002. Regulation of life-span by germ-line stem cells in Caenorhabditis elegans. Science 295:502-505. DOI: https://doi.org/10.1126/science.1065768, PMID: 11799246 Ashford TP, Porter KR. 1962. Cytoplasmic components in hepatic cell lysosomes. The Journal of Cell Biology 12:

198-202. DOI: https://doi.org/10.1083/jcb.12.1.198, PMID: 13862833

Brenner S. 1974. The genetics of Caenorhabditis elegans. Genetics 77:71-94. PMID: 4366476

Cebollero E, Reggiori F, Kraft C. 2012. Reticulophagy and ribophagy: regulated degradation of protein production factories. International Journal of Cell Biology 2012:182834. DOI: https://doi.org/10.1155/2012/ 182834, PMID: 22481944

Dargemont C, Ossareh-Nazari B. 2012. Cdc48/p97, a key actor in the interplay between autophagy and ubiquitin/proteasome catabolic pathways. Biochimica et Biophysica Acta (BBA) - Molecular Cell Research 1823: 138-144. DOI: https://doi.org/10.1016/j.bbamcr.2011.07.011, PMID: 21807033

Eskelinen EL, Reggiori F, Baba M, Kovács AL, Seglen PO. 2011. Seeing is believing: the impact of electron microscopy on autophagy research. Autophagy 7:935-956. DOl: https://doi.org/10.4161/auto.7.9.15760, PMID: 21566462

Floyd BE, Morriss SC, Maclntosh GC, Bassham DC. 2015. Evidence for autophagy-dependent pathways of rRNA turnover in Arabidopsis. Autophagy 11:2199-2212. DOI: https://doi.org/10.1080/15548627.2015.1106664, PMID: 26735434

Franks DM, Izumikawa T, Kitagawa H, Sugahara K, Okkema PG. 2006. C. elegans pharyngeal morphogenesis requires both de novo synthesis of pyrimidines and synthesis of heparan sulfate proteoglycans. Developmental Biology 296:409-420. DOI: https://doi.org/10.1016/j.ydbio.2006.06.008, PMID: 16828468

Grant B, Hirsh D. 1999. Receptor-mediated endocytosis in the Caenorhabditis elegans oocyte. Molecular Biology of the Cell 10:4311-4326. DOI: https://doi.org/10.1091/mbc.10.12.4311, PMID: 10588660

Guo P, Hu T, Zhang J, Jiang S, Wang X. 2010. Sequential action of Caenorhabditis elegans Rab GTPases regulates phagolysosome formation during apoptotic cell degradation. PNAS 107:18016-18021. DOI: https:// doi.org/10.1073/pnas.1008946107, PMID: 20921409

Hansen M, Hsu AL, Dillin A, Kenyon C. 2005. New genes tied to endocrine, metabolic, and dietary regulation of lifespan from a Caenorhabditis elegans genomic RNAi screen. PLoS Genetics 1:e17-28. DOI: https://doi.org/ 10.1371/journal.pgen.0010017, PMID: 16103914

Haud N, Kara F, Diekmann S, Henneke M, Willer JR, Hillwig MS, Gregg RG, Macintosh GC, Gärtner J, Alia A, Hurlstone AF. 2011. rnaset2 mutant zebrafish model familial cystic leukoencephalopathy and reveal a role for RNase T2 in degrading ribosomal RNA. PNAS 108:1099-1103. DOI: https://doi.org/10.1073/pnas.1009811107, PMID: 21199949

Henneke M, Diekmann S, Ohlenbusch A, Kaiser J, Engelbrecht V, Kohlschütter A, Krätzner R, Madruga-Garrido M, Mayer M, Opitz L, Rodriguez D, Rüschendorf F, Schumacher J, Thiele H, Thoms S, Steinfeld R, Nürnberg P, Gärtner J. 2009. RNASET2-deficient cystic leukoencephalopathy resembles congenital cytomegalovirus brain infection. Nature Genetics 41:773-775. DOI: https://doi.org/10.1038/ng.398, PMID: 19525954

Huang H, Kawamata T, Horie T, Tsugawa H, Nakayama Y, Ohsumi Y, Fukusaki E. 2015. Bulk RNA degradation by nitrogen starvation-induced autophagy in yeast. The EMBO Journal 34:154-168. DOI: https://doi.org/10. 15252/embj.201489083, PMID: 25468960 
Huang M, Graves LM. 2003. De novo synthesis of pyrimidine nucleotides; emerging interfaces with signal transduction pathways. Cellular and Molecular Life Sciences 60:321-336. DOI: https://doi.org/10.1007/ s000180300027, PMID: 12678497

Kamath RS, Ahringer J. 2003. Genome-wide RNAi screening in Caenorhabditis elegans. Methods 30:313-321. DOI: https://doi.org/10.1016/S1046-2023(03)00050-1, PMID: 12828945

Kang C, You YJ, Avery L. 2007. Dual roles of autophagy in the survival of Caenorhabditis elegans during starvation. Genes \&amp; Development 21:2161-2171. DOI: https://doi.org/10.1101/gad.1573107, PMID: 177 85524

Kawata Y, Sakiyama F, Hayashi F, Kyogoku Y. 1990. Identification of two essential histidine residues of ribonuclease T2 from Aspergillus oryzae. European Journal of Biochemistry 187:255-262. DOI: https://doi.org/ 10.1111/j.1432-1033.1990.tb15303.x, PMID: 2298207

Kenyon C, Chang J, Gensch E, Rudner A, Tabtiang R. 1993. A C. elegans mutant that lives twice as long as wild type. Nature 366:461-464. DOI: https://doi.org/10.1038/366461a0, PMID: 8247153

Kraft C, Deplazes A, Sohrmann M, Peter M. 2008. Mature ribosomes are selectively degraded upon starvation by an autophagy pathway requiring the Ubp3p/Bre5p ubiquitin protease. Nature Cell Biology 10:602-610. DOI: https://doi.org/10.1038/ncb1723, PMID: 18391941

Kraft C, Peter M. 2008. Is the Rsp5 ubiquitin ligase involved in the regulation of ribophagy? Autophagy 4:838840. DOI: https://doi.org/10.4161/auto.6603, PMID: 18670191

Lafontaine DL. 2010. A 'garbage can' for ribosomes: how eukaryotes degrade their ribosomes. Trends in Biochemical Sciences 35:267-277. DOI: https://doi.org/10.1016/j.tibs.2009.12.006, PMID: 20097077

Levine B, Mizushima N, Virgin HW. 2011. Autophagy in immunity and inflammation. Nature 469:323-335. DOI: https://doi.org/10.1038/nature09782, PMID: 21248839

Lin L, Yang P, Huang X, Zhang H, Lu Q, Zhang H. 2013. The scaffold protein EPG-7 links cargo-receptor complexes with the autophagic assembly machinery. The Journal of Cell Biology 201:113-129. DOI: https:// doi.org/10.1083/jcb.201209098, PMID: 23530068

Liu B, Du H, Rutkowski R, Gartner A, Wang X. 2012. LAAT-1 is the lysosomal lysine/arginine transporter that maintains amino acid homeostasis. Science 337:351-354. DOI: https://doi.org/10.1126/science.1220281, PMID: 22822152

Lu Q, Yang P, Huang X, Hu W, Guo B, Wu F, Lin L, Kovács AL, Yu L, Zhang H. 2011. The WD40 repeat Ptdlns(3)Pbinding protein EPG-6 regulates progression of omegasomes to autophagosomes. Developmental Cell 21: 343-357. DOI: https://doi.org/10.1016/j.devcel.2011.06.024, PMID: 21802374

Luhtala N, Parker R. 2010. T2 Family ribonucleases: ancient enzymes with diverse roles. Trends in Biochemical Sciences 35:253-259. DOI: https://doi.org/10.1016/j.tibs.2010.02.002, PMID: 20189811

Merry A, Qiao M, Hasler M, Kuwabara PE. 2014. RAD-6: pyrimidine synthesis and radiation sensitivity in Caenorhabditis elegans. Biochemical Journal 458:343-353. DOI: https://doi.org/10.1042/BJ20131085, PMID: 24262006

Mizushima N. 2009. Physiological functions of autophagy. Current Topics in Microbiology and Immunology 335 : 71-84. DOI: https://doi.org/10.1007/978-3-642-00302-8_3, PMID: 19802560

Murphy CT, Hu PJ. 2013. Insulin/insulin-like growth factor signaling in C. elegans. WormBook:1-43. DOI: https:// doi.org/10.1895/wormbook.1.164.1, PMID: 24395814

Nakatogawa H, Suzuki K, Kamada Y, Ohsumi Y. 2009. Dynamics and diversity in autophagy mechanisms: lessons from yeast. Nature Reviews Molecular Cell Biology 10:458-467. DOI: https://doi.org/10.1038/nrm2708, PMID: 19491929

Ossareh-Nazari B, Bonizec M, Cohen M, Dokudovskaya S, Delalande F, Schaeffer C, Van Dorsselaer A, Dargemont C. 2010. Cdc48 and Ufd3, new partners of the ubiquitin protease Ubp3, are required for ribophagy. EMBO reports 11:548-554. DOI: https://doi.org/10.1038/embor.2010.74, PMID: 20508643

Ossareh-Nazari B, Niño CA, Bengtson MH, Lee JW, Joazeiro CA, Dargemont C. 2014. Ubiquitylation by the Ltn1 E3 ligase protects $60 \mathrm{~S}$ ribosomes from starvation-induced selective autophagy. The Journal of Cell Biology 204:909-917. DOI: https://doi.org/10.1083/jcb.201308139, PMID: 24616224

Riddle DL, Blumenthal T, Meyer BJ, Priess JR. 1997. C. Elegans II, Plainview. New York: Cold Spring harvor Laboratory Press.

Sato K, Sato M, Audhya A, Oegema K, Schweinsberg P, Grant BD. 2006. Dynamic regulation of caveolin-1 trafficking in the germ line and embryo of Caenorhabditis elegans. Molecular Biology of the Cell 17:30853094. DOI: https://doi.org/10.1091/mbc.e06-03-0211, PMID: 16672374

Seranova E, Connolly KJ, Zatyka M, Rosenstock TR, Barrett T, Tuxworth RI, Sarkar S. 2017. Dysregulation of autophagy as a common mechanism in lysosomal storage diseases. Essays In Biochemistry 61:733-749. DOI: https://doi.org/10.1042/EBC20170055, PMID: 29233882

Sun T, Wang X, Lu Q, Ren H, Zhang H. 2011. CUP-5, the C. elegans ortholog of the mammalian lysosomal channel protein MLN1/TRPML1, is required for proteolytic degradation in autolysosomes. Autophagy 7:13081315. DOI: https://doi.org/10.4161/auto.7.11.17759, PMID: 21997367

Tian E, Wang F, Han J, Zhang H. 2009. epg-1 functions in autophagy-regulated processes and may encode a highly divergent Atg13 homolog in C. elegans. Autophagy 5:608-615. DOI: https://doi.org/10.4161/auto.5.5. 8624, PMID: 19377305

Tian Y, Li Z, Hu W, Ren H, Tian E, Zhao Y, Lu Q, Huang X, Yang P, Li X, Wang X, Kovács AL, Yu L, Zhang H. 2010. C. elegans screen identifies autophagy genes specific to multicellular organisms. Cell 141:1042-1055. DOI: https://doi.org/10.1016/j.cell.2010.04.034, PMID: 20550938 
Wyant GA, Abu-Remaileh M, Frenkel EM, Laqtom NN, Dharamdasani V, Lewis CA, Chan SH, Heinze I, Ori A, Sabatini DM. 2018. NUFIP1 is a ribosome receptor for starvation-induced ribophagy. Science 360:751-758. DOI: https://doi.org/10.1126/science.aar2663, PMID: 29700228

Xie Z, Klionsky DJ. 2007. Autophagosome formation: core machinery and adaptations. Nature Cell Biology 9 : 1102-1109. DOI: https://doi.org/10.1038/ncb1007-1102, PMID: 17909521

Yang Z, Klionsky DJ. 2010. Mammalian autophagy: core molecular machinery and signaling regulation. Current Opinion in Cell Biology 22:124-131. DOI: https://doi.org/10.1016/j.ceb.2009.11.014, PMID: 20034776

Zhang Y, Yan L, Zhou Z, Yang P, Tian E, Zhang K, Zhao Y, Li Z, Song B, Han J, Miao L, Zhang H. 2009. SEPA-1 mediates the specific recognition and degradation of $\mathrm{P}$ granule components by autophagy in $\mathrm{C}$. elegans. Cell 136:308-321. DOI: https://doi.org/10.1016/j.cell.2008.12.022, PMID: 19167332

Zhao Y, Tian E, Zhang H. 2009. Selective autophagic degradation of maternally-loaded germline P granule components in somatic cells during C. elegans embryogenesis. Autophagy 5:717-719. DOl: https://doi.org/10. 4161/auto.5.5.8552, PMID: 19372764 